\title{
Fluorescent Peptide Dendrimers for siRNA Transfection: Tracking pH Responsive Aggregation, siRNA Binding, and Cell Penetration
}

\author{
Marc Heitz, Susanna Zamolo, Sacha Javor, and Jean-Louis Reymond* \\ Cite This: Bioconjugate Chem. 2020, 31, 1671-1684 \\ Read Online
}

ABSTRACT: Transfecting nucleic acids into various cells is a key procedure in biological research also envisioned for therapeutic applications. In our effort to obtain simple reagents that would be readily accessible from commercial building blocks, we recently reported peptide dendrimers as single component siRNA transfection reagents accessible in pure form by solid-phase peptide synthesis. Here, we extend our studies of these dendrimers by identifying analogs bearing a coumarin or BODIPY fluorescent label in their core and displaying comparable siRNA transfection efficiencies, $\mathrm{pH}$ dependent aggregation, siRNA binding, and secondary structures. Fluorescence resonance energy transfer

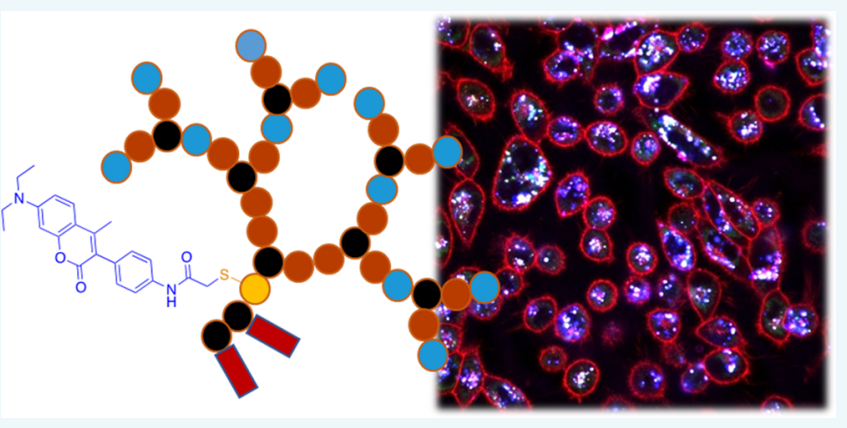
(FRET) studies show that the dendrimers are tightly associated with siRNA within the formed nanoparticles at $\mathrm{pH} 7.4$ but are released into solution at $\mathrm{pH} 5.0$ and can participate in endosome escape by destabilizing the membrane at this $\mathrm{pH}$ value. Colocalization studies furthermore suggest that peptide dendrimers and siRNA remain tightly associated throughout the transfection process.

\section{INTRODUCTION}

Transfecting cells with nucleic acids to modulate protein expression is an essential procedure in biological research also envisioned for therapeutic applications. ${ }^{1-5}$ A broad variety of hydrophobic polycations have been developed as transfection reagents to overcome limitations of viral vectors in terms of safety and genetic variability, ${ }^{6-9}$ spanning from lipids ${ }^{10-14}$ to polymers, ${ }^{15-21}$ dendrimers, ${ }^{22-27}$ and nanoparticles; ${ }^{28-32}$ however, many of these reagents are polymeric mixtures or complex reagents requiring nonstandard syntheses, which limits transferability of results.

In our effort to obtain simple reagents that would be readily accessible from commercial building blocks, we have developed transfection reagents based on lysine branched peptide dendrimers accessible in pure form by solid-phase peptide synthesis. ${ }^{33-35}$ We initially discovered peptide dendrimers with specific amino acid sequences in their branches enabling either DNA or siRNA transfection when used in combination with lipofectin. ${ }^{36-38}$ Introducing hydrophobic groups at the dendrimer core, in particular, fatty acids similarly to the approach taken by others to optimize cell penetrating peptides for membrane interaction and selfassembly, ${ }^{39-41}$ later enabled us to obtain dendrimers acting as single component siRNA transfection reagents. We obtained the best siRNA transfection activities with D-enantiomeric dendrimers DMH13 with a pair of palmitic acids and DMH18 with a leucine tetrapeptide as hydrophobic cores (Figure 1a). ${ }^{42}$ Mechanistic studies showed that DMH13 and DMH18 aggregate at neutral $\mathrm{pH}$ via intermolecular $\beta$-sheets to form nanoparticles in combination with siRNA, which enter cells by endocytosis. Endosome acidification then induces the protonation of the dendrimer amino termini, which triggers a conformational rearrangement of the peptide dendrimer to an $\alpha$-helical conformation and a rearrangement of the nanoparticle with partial release of free dendrimer with membrane disruptive activity, inducing endosome escape and delivery of the siRNA cargo into the cytosol (Figure 1b). ${ }^{42}$

Despite our detailed previous investigations, important aspects of the proposed transfection mechanism remained speculative because DMH13 and DMH18 could not be tracked directly during siRNA complexation and transfection. We therefore set out to identify fluorescence labeled analogs to perform FRET based proximity studies and track the localization of the dendrimers during transfection. Indeed, various labeling studies reported on siRNA ${ }^{43-49}$ or transfection reagents ${ }^{39,50-52}$ have been shown to provide useful insight into the transfection process. Considering that a variety of dendrimer core modifications were compatible with siRNA transfection if the dendrimer branches were kept constant, we

Received: April 17, 2020

Revised: May 15, 2020

Published: May 18, 2020 


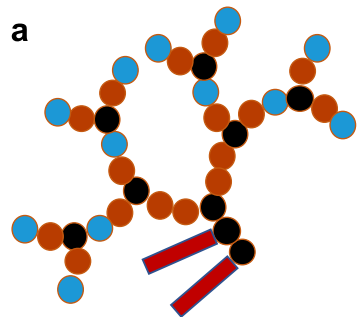

DMH13

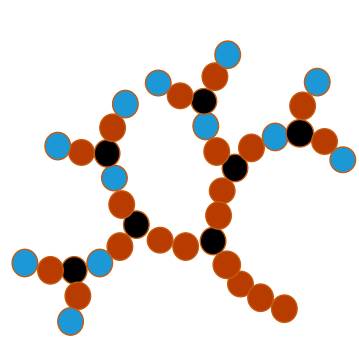

DMH18

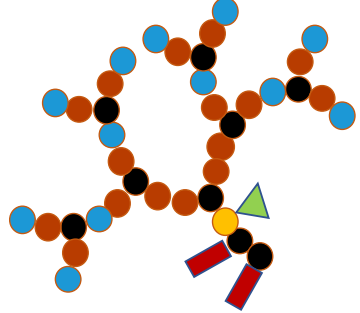

D1C/D1B
D-Lysine

D-Leucine

Branching D-Lysine

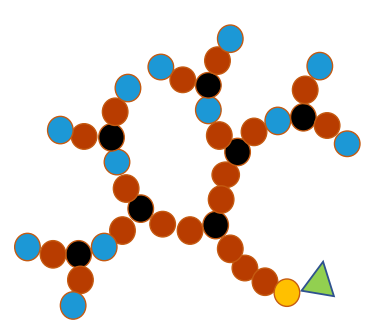

D3C/D3B

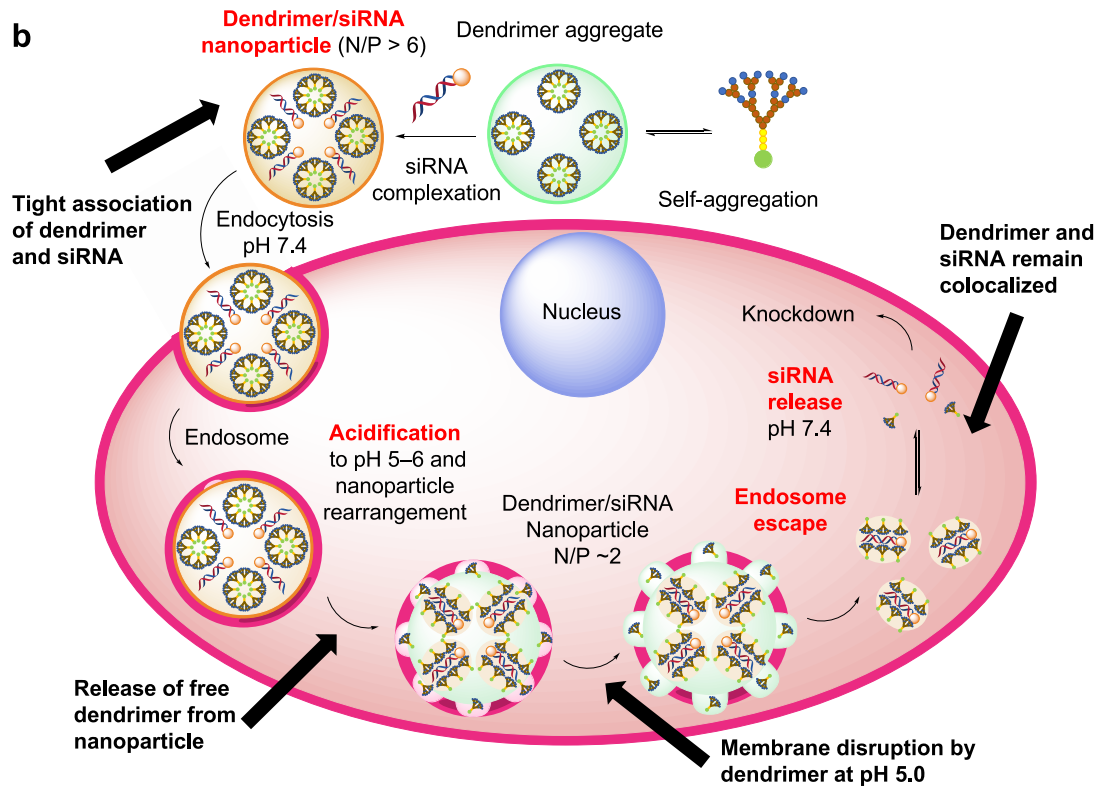

Figure 1. siRNA transfection mediated by peptide dendrimers as single component reagents. (a) Schematic structure of transfection dendrimers from previous study (DMH13/DMH18) and their fluorescent analogs discussed here (D1C/D1B, D3C/D3B). (b) Mechanism of peptide dendrimer mediated siRNA transfection. Black arrows indicate new insights reported here using fluorescence labeled dendrimers.

designed our fluorescently labeled dendrimers by modifying the dendrimer core with hydrophobic fluorescent labels.

Herein we detail the identification of siRNA transfection dendrimers bearing a coumarin (D1C/D3C) or BODIPY (D1B/D3B) label in their core and show that these labeled dendrimers display siRNA transfection and structure-property relationships that are comparable to their nonlabeled parent dendrimers DMH13 and DMH18. We then use these dendrimers to deepen our understanding of the transfection process by directly measuring the interaction between dendrimer and siRNA using fluorescence resonance energy transfer (FRET), by measuring their vesicle leakage activity under the low $\mathrm{pH}$ conditions of the endosome, and by monitoring the localization of both siRNA and transfection dendrimer within the cells during the transfection process by confocal microscopy.

\section{RESULTS AND DISCUSSION}

Identification of Fluorescent siRNA Transfection Dendrimers. We initially focused on 7-diethylamino-4methyl-3(4-acetamidophenyl)-coumarin $\left(\lambda_{\mathrm{ex}}=390 \mathrm{~nm}, \lambda_{\mathrm{em}}=\right.$ $470 \mathrm{~nm})$ as a fluorescent label, thereafter referred to as "coumarin", because it can be recorded using standard fluorescence microscopes without interference with the $\mathrm{Cy} 3$ fluorescent label for siRNA $\left(\lambda_{\mathrm{ex}}=530 \mathrm{~nm}, \lambda_{\mathrm{em}}=574 \mathrm{~nm}\right)$ and the Quant-it microRNA dye used to measure siRNA binding. ${ }^{53}$ To obtain fluorescent versions of our transfection dendrimers, we modified their sequence by inserting a cysteine residue at the dendrimer core and alkylating it with 7-diethylamino-4methyl-3(4-iodacetamidophenyl)-coumarin, ${ }^{54}$ simultaneously adjusting the composition of the core to obtain an optimal hydrophobicity for efficient siRNA transfection. 


\section{Scheme 1. Synthesis and Structure of $\mathrm{D}^{\mathrm{C}} \mathrm{C}^{\mathrm{a}}$}

$a, b$<smiles>CCNc1ccc2c(C)c(-c3ccc(NC(=O)CI)cc3)c(=O)oc2c1</smiles>

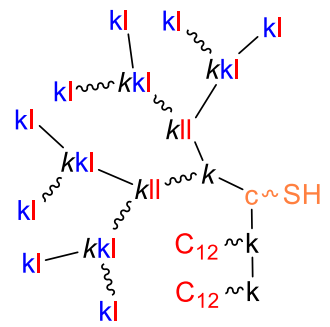

D1<smiles>CC(C)CC(=O)C(CC(C)C)NC(=O)[C@H](N)CCCC[NH3+]</smiles><smiles></smiles>

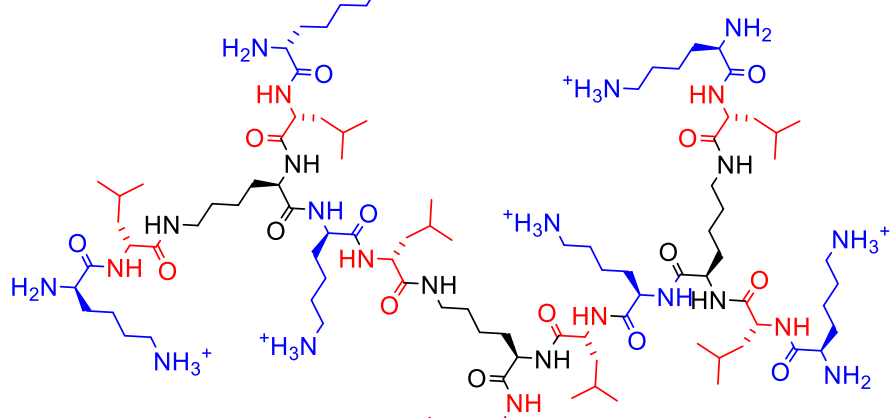
$\mathrm{NH}$<smiles>CCCCC(N)C(N)CCC</smiles>

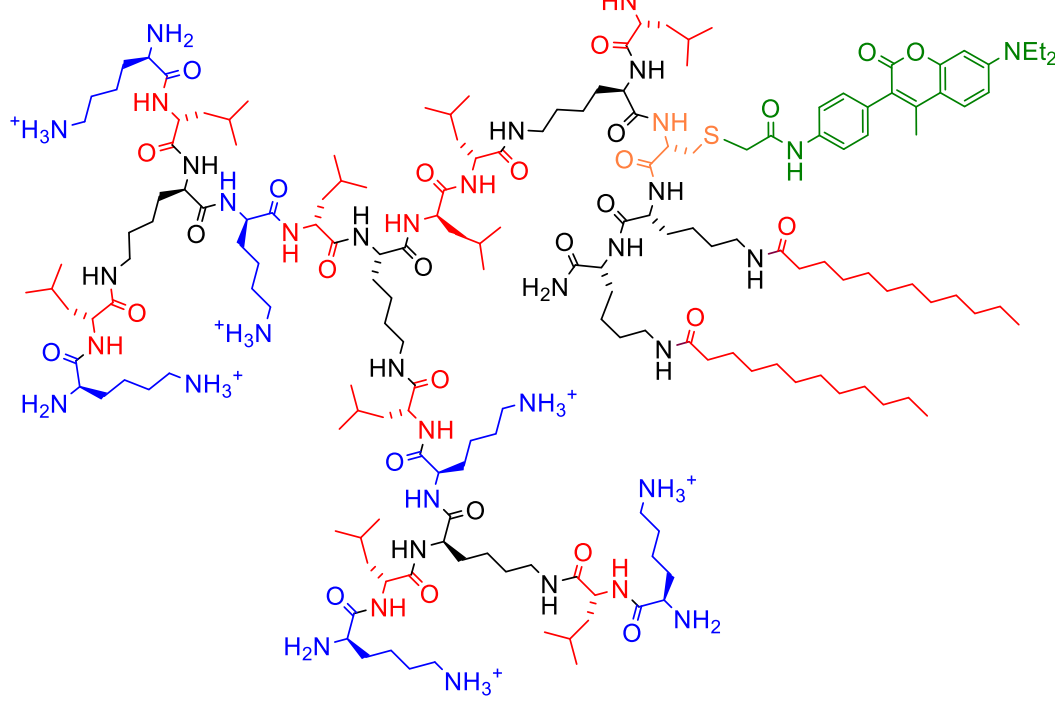

D1C

$(\mathrm{kl})_{8}(k \mathrm{kl})_{4}(k \mathrm{ll})_{2} \mathrm{kc}(\mathrm{Cmr}) \mathrm{k}\left(\mathrm{C}_{12}\right) \mathrm{k}\left(\mathrm{C}_{12}\right)$

${ }^{a}$ For intermediate D1, single letter codes indicate D-amino acids, connections indicate peptide bonds, and wobble connections indicate amide to the $\varepsilon$-amino group of lysine, $\mathrm{C}_{12}=$ lauroyl amide on lysine side chain. $\mathrm{D} 1 \mathrm{C}$ is shown with the protonation state at $\mathrm{pH}$ 7.4. Conditions: (a) (i) 5 equiv/coupling-site Fmoc-amino acid, 5 equiv/coupling site Oxyma, 5 equiv/coupling site DIC in DMF, $1-5$ min, $75-90{ }^{\circ} \mathrm{C}$; (ii) Piperidine/DMF $(1: 4, \mathrm{v} / \mathrm{v}), 2 \mathrm{~min}, 75-90^{\circ} \mathrm{C}$. (iii) $\mathrm{P}\left(\mathrm{PPh}_{3}\right)_{4}\left(0.25\right.$ equiv/alloc group), $\left(\mathrm{CH}_{3}\right)_{2} \mathrm{NH} \cdot \mathrm{BH}_{3}$ (25 equiv/alloc group), $2 \times 60 \mathrm{~min}, 25^{\circ} \mathrm{C}$; (iv) Palmitic acid (5 equiv/coupling site), DIC (5 equiv/coupling site), Oxyma (5 equiv/coupling site) in NMP, 60 min-overnight; (v) $\mathrm{CF}_{3} \mathrm{CO}_{2} \mathrm{H}(94 \%), i-$ $\mathrm{Pr}_{3} \mathrm{SiH}(2.5 \%)$, DODT (2.5\%), $\mathrm{H}_{2} \mathrm{O}(1 \%), 5 \mathrm{~h}, 25^{\circ} \mathrm{C}$. (b) Reversed phase $\mathrm{C}_{18}$ preparative HPLC, gradient $0-70 \% \mathrm{CH} \mathrm{H}_{3} \mathrm{CN} / \mathrm{H}_{2} \mathrm{O} / 0.1 \% \mathrm{TFA}$ over 45 min. (c) 1 equiv D1, 1.1 equiv (7)-diethylamino-3-[4-(iodoacetamido)phenyl]-4-methylcoumarin, in $\mathrm{H}_{2} \mathrm{O} / \mathrm{ACN}(1: 1, \mathrm{v} / \mathrm{v}), 120 \mathrm{~min}, 25{ }^{\circ} \mathrm{C}$.

For dendrimers MH13/DMH13 bearing two palmitoyl groups at their core, we inserted the cysteine residue before the first branching point as the fluorophore attachment point, while reducing the length of the pair of fatty acyl chains from $\mathrm{C}_{16}$ to $\mathrm{C}_{12}$ to adjust core hydrophobicity, providing dendrimers 1C/D1C. For MH18, which contains a tetra-leucine sequence as hydrophobic core, we inserted a cysteine residue at the first position of the core and gradually shortened the tetra-leucine sequence to form fluorescent versions $2 \mathrm{C}, 3 \mathrm{C}, 4 \mathrm{C}$, and $5 \mathrm{C}$. We also prepared fluorescent versions of two MH18 analogs with previously identified inactivating modifications in the dendrimer branches as negative controls, namely, 6C $(\mathrm{L} \rightarrow \mathrm{K}$ exchange in G1, reduces siRNA binding and abolishes transfection) and $7 \mathrm{C}(\mathrm{K} \rightarrow \mathrm{L}$ exchange in $\mathrm{G} 2$, induces 
Table 1. Synthesis, siRNA Binding, and Transfection with Fluorescence Labeled Peptide Dendrimers

\begin{tabular}{|c|c|c|c|c|c|c|c|}
\hline compound & sequence $^{a}$ & $\operatorname{pos}^{b}$ & hyd $^{c}$ & yield $^{d} \mathrm{mg}(\%)$ & MS $^{e}$ calc./obs. & free $\operatorname{siRNA} A^{f}[\%]$ & GAPDH $_{\text {activity }}^{g}[\%]$ \\
\hline $\mathbf{L} 2000^{h}$ & n.a. & n.a. & n.a. & n.a. & n.a. & $32.2 \pm 2$ & $34 \pm 4$ \\
\hline $\mathrm{MH}_{13}{ }^{h}$ & $(\mathrm{KL})_{8}(\mathrm{KKL})_{4}(\mathrm{KLL})_{2} \mathrm{KK}\left(\mathrm{C}_{16}\right) \mathrm{K}\left(\mathrm{C}_{16}\right)$ & 12 & 20 & $26.8(4)$ & $4992.83 / 4992.82$ & $4.8 \pm 0.7$ & $32 \pm 5$ \\
\hline 1 & $(\mathrm{KL})_{8}(\mathrm{KKL})_{4}(\mathrm{KLL})_{2} \mathrm{KCK}\left(\mathrm{C}_{12}\right) \mathrm{K}\left(\mathrm{C}_{12}\right)$ & 12 & 18 & $34.2(5)$ & $4983.71 / 4983.71$ & & \\
\hline 1C & $(\mathrm{KL})_{8}(\mathrm{KKL})_{4}(\mathrm{KLL})_{2} \mathrm{KC}(\mathrm{Cmr}) \mathrm{K}\left(\mathrm{C}_{12}\right) \mathrm{K}\left(\mathrm{C}_{12}\right)$ & 12 & 18 & $3.6(42)$ & $5345.87 / 5345.88$ & $1.7 \pm 0.2$ & $34 \pm 13$ \\
\hline DMH13 $^{h}$ & $(\mathrm{kl})_{8}(k \mathrm{kl})_{4}(k \mathrm{ll})_{2} k \mathrm{k}\left(\mathrm{C}_{16}\right) \mathrm{k}\left(\mathrm{C}_{16}\right)$ & 12 & 20 & $128.4(7)$ & $4992.83 / 4992.84$ & $3.9 \pm 0.5$ & $31 \pm 2$ \\
\hline D1 & $(\mathrm{kl})_{8}(k \mathrm{kl})_{4}(k \mathrm{ll})_{2} k \mathrm{ck}\left(\mathrm{C}_{12}\right) \mathrm{k}\left(\mathrm{C}_{12}\right)$ & 12 & 18 & $62(10)$ & $4983.71 / 4983.71$ & & \\
\hline D1C & $(\mathrm{kl})_{8}(k \mathrm{kl})_{4}(k \mathrm{ll})_{2} k \mathrm{c}(\mathrm{Cmr}) \mathrm{k}\left(\mathrm{C}_{12}\right) \mathrm{k}\left(\mathrm{C}_{12}\right)$ & 12 & 18 & $3.4(33)$ & $5345.87 / 5345.89$ & $1.6 \pm 0.1$ & $24 \pm 5$ \\
\hline MH18 $^{h}$ & $(\mathrm{KL})_{8}(K \mathrm{KL})_{4}(\mathrm{KLL})_{2} \mathrm{KLLLL}$ & 12 & 20 & $52.7(8)$ & $4712.51 / 4712.52$ & $4.8 \pm 0.4$ & $28 \pm 9$ \\
\hline 2 & $(\mathrm{KL})_{8}(\mathrm{KKL})_{4}(\mathrm{KLL})_{2} \mathrm{KLLLLC}$ & 12 & 20 & $27(4)$ & $4815.52 / 4815.55$ & $2.7 \pm 0.3$ & $69 \pm 18$ \\
\hline $2 \mathrm{C}$ & $(\mathrm{KL})_{8}(\mathrm{KKL})_{4}(\mathrm{KLL})_{2} \mathrm{KLLLLC}(\mathrm{Cmr})$ & 12 & 20 & $1.7(32)$ & $5177.68 / 5177.69$ & $1.6 \pm 0.2$ & $75 \pm 20$ \\
\hline 3 & $(\mathrm{KL})_{8}(\mathrm{KKL})_{4}(\mathrm{KLL})_{2} \mathrm{KLLLC}$ & 12 & 19 & $33.4(7)$ & $4702.44 / 4702.45$ & $3.7 \pm 0.3$ & $55 \pm 2$ \\
\hline $3 \mathrm{C}$ & $(\mathrm{KL})_{8}(\mathrm{KKL})_{4}(\mathrm{KLL})_{2} \mathrm{KLLLC}(\mathrm{Cmr})$ & 12 & 19 & $2.1(42)$ & $5064.60 / 5064.61$ & $2.9 \pm 0.1$ & $33 \pm 3$ \\
\hline 4 & $(\mathrm{KL})_{8}(\mathrm{KKL})_{4}(\mathrm{KLL})_{2} \mathrm{KLLC}$ & 12 & 18 & $57.2(8)$ & $4589.35 / 4589.36$ & & \\
\hline $4 \mathrm{C}$ & $(\mathrm{KL})_{8}(\mathrm{KKL})_{4}(\mathrm{KLL})_{2} \mathrm{KLLC}(\mathrm{Cmr})$ & 12 & 18 & $3.6(35)$ & $4951.52 / 4951.53$ & $3.8 \pm 0.5$ & $52 \pm 0$ \\
\hline 5 & $(\mathrm{KL})_{8}(\mathrm{KKL})_{4}(\mathrm{KLL})_{2} \mathrm{KC}$ & 12 & 16 & $7(2)$ & $4363.19 / 4363.19$ & & \\
\hline $5 \mathrm{C}$ & $(\mathrm{KL})_{8}(\mathrm{KKL})_{4}(\mathrm{KLL})_{2} \mathrm{KC}(\mathrm{Cmr})$ & 12 & 16 & $2.8(26)$ & $4725.35 / 4725.36$ & $4.1 \pm 0.1$ & $89 \pm 5$ \\
\hline DMH18 $^{h}$ & $(\mathrm{kl})_{8}(k \mathrm{kl})_{4}(k \mathrm{ll})_{2} k \mathrm{llll}$ & 12 & 20 & $73.6(11)$ & $4712.51 / 4712.52$ & $4.6 \pm 0.7$ & $28 \pm 9$ \\
\hline D3 & $(\mathrm{kl})_{8}(k \mathrm{kl})_{4}(k \mathrm{ll})_{2} k \mathrm{lll} \mathrm{c}$ & 12 & 19 & $129.5(21)$ & $4702.44 / 4702.48$ & $3.2 \pm 0.1$ & $33 \pm 1$ \\
\hline D3C & $(\mathrm{kl})_{8}(k \mathrm{kl})_{4}(k \mathrm{ll})_{2} k \mathrm{lll} \mathrm{c}(\mathrm{Cmr})$ & 12 & 19 & $6.6(32)$ & $5064.60 / 5064.62$ & $2.7 \pm 0.3$ & $24 \pm 2$ \\
\hline MH46 $^{h}$ & $(\mathrm{KL})_{8}(\mathrm{KKL})_{4}(\mathrm{KKL})_{2} \mathrm{KLLLL}$ & 14 & 18 & $8.5(2)$ & $4742.53 / 4742.55$ & $7.7 \pm 0.9$ & $90 \pm 9$ \\
\hline 6 & $(\mathrm{KL})_{8}(\mathrm{KKL})_{4}(\mathrm{KKL})_{2} \mathrm{KLLLC}$ & 14 & 17 & $47.2(10)$ & $4732.46 / 4732.46$ & & \\
\hline $6 \mathrm{C}$ & $(\mathrm{KL})_{8}(\mathrm{KKL})_{4}(\mathrm{KKL})_{2} \mathrm{KLLLC}(\mathrm{Cmr})$ & 14 & 17 & $2.8(31)$ & $5094.62 / 5064.64$ & $6.9 \pm 0.6$ & $68 \pm 4$ \\
\hline $\mathrm{MH}_{4} 7^{h}$ & $(\mathrm{KL})_{8}(K \mathrm{LL})_{4}(\mathrm{KLL})_{2} K L L L L$ & 8 & 24 & $10.1(2)$ & $4652.47 / 4652.49$ & $3 \pm 0.1$ & $77 \pm 14$ \\
\hline 7 & $(\mathrm{KL})_{8}(\mathrm{KLL})_{4}(\mathrm{KLL})_{2} \mathrm{KLLLC}$ & 8 & 23 & $65.1(14)$ & $4642.39 / 4642.40$ & & \\
\hline $7 \mathrm{C}$ & $(\mathrm{KL})_{8}(\mathrm{KLL})_{4}(\mathrm{KLL})_{2} \mathrm{KLLLC}(\mathrm{Cmr})$ & 8 & 23 & $3.9(37)$ & $5004.56 / 5004.58$ & $1.3 \pm 0.1$ & $71 \pm 5$ \\
\hline $1 \mathrm{~B}$ & $(\mathrm{KL})_{8}(\mathrm{KKL})_{4}(\mathrm{KLL})_{2} \mathrm{KC}(\mathrm{Bdp}) \mathrm{K}\left(\mathrm{C}_{12}\right) \mathrm{K}\left(\mathrm{C}_{12}\right)$ & 12 & 18 & $2.9(35)$ & $5244.85 / 5243.83$ & n.a. & $39 \pm 7$ \\
\hline D1B & $(\mathrm{kl})_{8}(k \mathrm{kl})_{4}(k \mathrm{ll})_{2} k \mathrm{c}(\mathrm{Bdp}) \mathrm{k}\left(\mathrm{C}_{12}\right) \mathrm{k}\left(\mathrm{C}_{12}\right)$ & 12 & 18 & $2.4(29)$ & $5244.85 / 5243.83$ & n.a. & $37 \pm 0$ \\
\hline 3B & $(\mathrm{KL})_{8}(\mathrm{KKL})_{4}(\mathrm{KLL})_{2} \mathrm{KLLLC}(\mathrm{Bdp})$ & 12 & 19 & $3.1(37)$ & $4963.57 / 4962.55$ & n.a. & $30 \pm 3$ \\
\hline D3B & $(\mathrm{kl})_{8}(k \mathrm{kl})_{4}(k \mathrm{ll})_{2} k \mathrm{lll} \mathrm{c}(\mathrm{Bdp})$ & 12 & 19 & $2.6(31)$ & $4963.57 / 4962.56$ & n.a. & $34 \pm 2$ \\
\hline $6 B$ & $(\mathrm{KL})_{8}(\mathrm{KKL})_{4}(\mathrm{KKL})_{2} K \mathrm{LLLC}(\mathrm{Bdp})$ & 14 & 17 & $4.0(47)$ & $4903.53 / 4902.55$ & n.a. & $95 \pm 8$ \\
\hline $7 \mathrm{~B}$ & $(\mathrm{KL})_{8}(\mathrm{KLL})_{4}(\mathrm{KLL})_{2} \mathrm{KLLLC}(\mathrm{Bdp})$ & 8 & 23 & $4.9(63)$ & $4993.60 / 4992.60$ & n.a. & $80 \pm 5$ \\
\hline
\end{tabular}

${ }^{a}$ One-letter-code amino acids, $\mathrm{K}$ is the branching lysine residue, $\mathrm{C}$-termini are carboxamide $\mathrm{CONH}_{2}$, all $\mathrm{N}$-termini are free. Three-letter-code short names are used for fluorophores coupled to peptide dendrimers: 7-Diethylamino-3-[4-(iodoacetamido)phenyl]-4-methylcoumarin (Cmr), 8Bromomethyl-4,4-Difluoro-1,3,5,7-Tetramethyl-4-Bora-3a-4a-Diaza-s-Indacene (Bdp). ${ }^{b} \mathrm{Pos}=$ number of positive charges estimated at neutral $\mathrm{pH}$, +1 for lysine, N-termini as $\mathrm{NH}_{2}$ at neutral $\mathrm{pH}$. ${ }^{c} \mathrm{Hyd}=$ number of hydrophobic side chains. Leucine $=1$, Lys $\left(\mathrm{C}_{16}\right)=2 .{ }^{d}$ Isolated yields as trifluoroacetate salt after preparative HPLC purification. ${ }^{e}$ ESI-MS, see also the Supporting Information. ${ }^{f}$ Fluorescence from intercalation in siRNA $(20 \mathrm{nM})$ in complex with peptide dendrimer $(\mathrm{N} / \mathrm{P} 10,420 \mathrm{nM}, 3 \mu \mathrm{g} / \mathrm{mL})$ or L2000 $(2: 1,532 \mathrm{ng} / \mathrm{mL})$ by Quant-it microRNA performed in triplicate and normalized to the value of siRNA alone. ${ }^{g}$ GAPDH activity in HeLa cells after $4 \mathrm{~h}$ transfection by siRNA (100 nM) and peptide dendrimers $(\mathrm{N} / \mathrm{P} 10,2.1 \mu \mathrm{M}, 15 \mu \mathrm{g} / \mathrm{mL})$ or L2000 $(2: 1,2.66 \mu \mathrm{g} / \mathrm{mL})$ followed by $48 \mathrm{~h}$ incubation in DMEM supplemented with $10 \%$ FCS and normalized to siNC (negative control). ${ }^{h}$ Data and analysis present in previous report. ${ }^{42}$ Experiments were carried out in triplicate in three independent experiments. Bar graph representation and parallel transfection with siNC are shown in Figure S1. n.a. = not applicable. Missing entries were not determined.

stronger siRNA binding preventing its release and knock-down activity). We synthesized all dendrimers by automated solidphase peptide synthesis (SPPS) followed by preparative RPHPLC purification. We performed cysteine alkylation in aqueous acetonitrile under slightly alkaline conditions and purified the final product by preparative RP-HPLC (Scheme 1, Scheme S1 and Table 1).

For transfection studies, we used a 21 nucleotide doublestranded siRNA for knocking down glyceraldehyde phosphate dehydrogenase $(\mathrm{GADPH}){ }^{55,56}$ We measured siRNA binding using the fluorogenic intercalating dye Quant-it microRNA ${ }^{53}$ and knock-down efficiency by measuring GADPH activity in HeLa cells, a standard cell line for transfection studies, using a chromogenic reporter system ${ }^{57-59}$ after $4 \mathrm{~h}$ transfection with dendrimer/siRNA complexes at $100 \mathrm{nM}$ siRNA and $\mathrm{N} / \mathrm{P}=10$, and $48 \mathrm{~h}$ incubation, in comparison with the same experiment using a scrambled sequence mock siRNA (
Fluorescent dendrimers 1C/D1C bound and transfected siRNA to a comparable extent to their parent dendrimers MH13/DMH13 and the reference reagent lipofectamine 2000 (L2000). The D-enantiomeric D1C showed a slightly stronger activity than 1C, which reproduced the previously observed stronger activity of DMH13 over MH13. In the case of the fluorescent version of $\mathrm{MH18}$, dendrimers 2C, 3C, 4C, and 5C bound siRNA as tightly as the parent dendrimer as indicated by only very low residual Quant-it microRNA fluorescence. However, only 3C, with three leucine residues in its core, matched MH18 in terms of transfection efficiency. We therefore also prepared D-enantiomeric dendrimer D3C, which turned out slightly more active than the L-enantiomer 3C in terms of knock-down, reproducing the difference between the previously reported MH18 and DMH18. Finally, fluorescent dendrimers $6 \mathrm{C}$ and $7 \mathrm{C}$ designed as negative controls displayed the expected siRNA binding and absence of GADPH knock-down. 

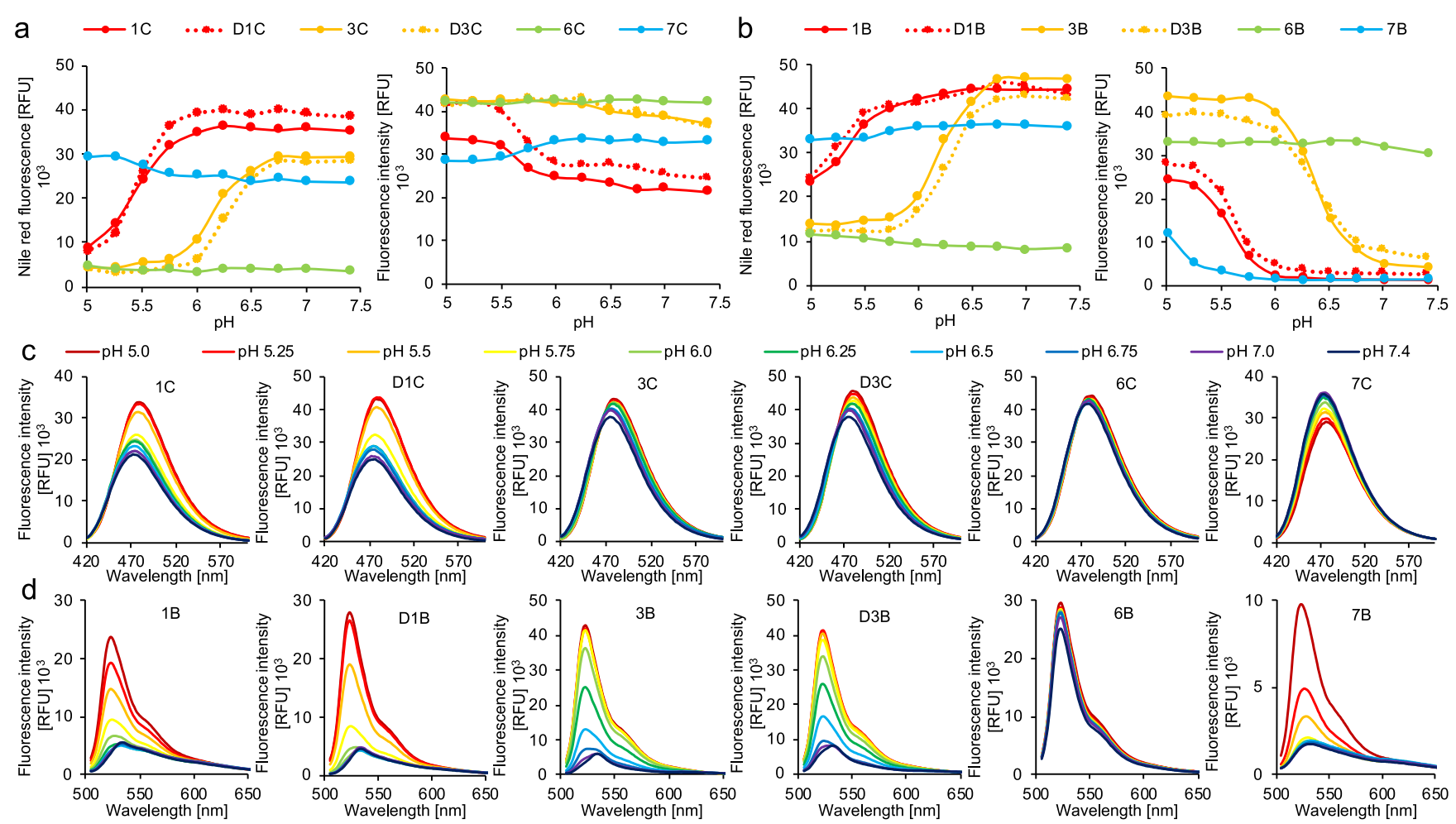

Figure 2. $\mathrm{pH}$ dependent aggregation of peptide dendrimers: (a) coumarin or (b) BODIPY peptide dendrimer $(100 \mu \mathrm{g} / \mathrm{mL})$ in $\mathrm{PB}$ at $\mathrm{pH} 5.0-7.4$ added on dried Nile red (final concentration of $0.2 \mu \mathrm{M}$ ). Fluorescence measured at $\lambda_{\mathrm{ex}} / \lambda_{\mathrm{em}}=540 / 615 \mathrm{~nm}$ for Nile red and of the fluorophore attached to the dendrimer after the similar serial dilution at $\lambda_{\mathrm{ex}} / \lambda_{\mathrm{em}}=390 / 470 \mathrm{~nm}$ for coumarin and at $\lambda_{\mathrm{ex}} / \lambda_{\mathrm{em}}=493 / 520 \mathrm{~nm}$ for BODIPY. Fluorescence scans of $(\mathrm{c})$ coumarin or (d) BODIPY labeled peptide dendrimers $(100 \mu \mathrm{g} / \mathrm{mL})$ in PB at pH 5.0-7.4 with excitation wavelengths at $\lambda_{\mathrm{ex}}=390 \mathrm{~nm}$ for coumarin and at $\lambda_{\mathrm{ex}}=493 \mathrm{~nm}$ for BODIPY. RFU $=$ Relative fluorescence unit.

In view of performing fluorescence resonance energy transfer (FRET) studies between Cy3-labeled siRNA and our dendrimers, we prepared analogs of the $1 \mathrm{C} / \mathrm{D} 1 \mathrm{C}, 3 \mathrm{C} / \mathrm{D} 3 \mathrm{C}$, 6C, and 7C dendrimers carrying a BODIPY (1B/D1B, 3B/ D3B as 6B and $\left.7 \mathrm{~B}, \mathrm{Bdp}, \lambda_{\mathrm{ex}}=493 \mathrm{~nm}, \lambda_{\mathrm{em}}=520 \mathrm{~nm}\right)$. These BODIPY labeled dendrimers were obtained by alkylation of cysteine intermediates 10, D10, 4, D4, 6, and 7 with 8bromomethyl-4,4-difluoro-1,3,5,7-tetramethyl-4-bora-3a-4adiaza-s-Indacene. ${ }^{60}$ While siRNA binding could not be assessed in this series due to interference of BODIPY with the Quant-it microRNA assay, these fluorescent dendrimers displayed the expected siRNA transfection efficiencies, although there were no significant differences between L- and D-enantiomers in this series. On the other hand, labeling with dansyl, bimane, methoxyphenyloxazolylpyridinium, and aminofluorescein abolished transfection with MH18 analogs and only partially preserved it for analogs of its enantiomer DMH18 (Table S1). Additional fluorescent labels (Pyrene, Cyanine 7, and Cyanine 7.5) and dendrimers were also investigated but mostly showed only modest transfection activities (Table S2).

Taken together, these experiments showed that fluorescent versions of our transfection dendrimers labeled with coumarin and BODIPY largely preserved siRNA binding and transfection abilities, including their negative controls. Similar properties were observed in $\mathrm{CHO}$ and HEK-293 cells, another two cell lines often used for transfection studies (Figure S2). In all cases, there was no significant difference in GADPH activity between cells treated with dendrimer complexes of scrambled siRNA and untreated cells, suggesting that our fluorescent dendrimers did not affect cell viability (Figure S1), which was verified further by a dedicated cell viability assay in the case of the coumarin labeled analogs (Figure S3).

For further investigations, we selected 1C/D1C and 1B/ D1B as fluorescent versions of transfection dendrimers MH13/DMH13 with a lipidated core and 3C/D3C and 3B/ D3B as fluorescent versions of transfection dendrimers MH18/DMH18 with an oligoleucine core. We also included the above-mentioned negative controls $6 \mathrm{C} / 6 \mathrm{~B}$ and $7 \mathrm{C} / 7 \mathrm{~B}$.

pH Dependent Aggregation, Secondary Structure Content, and siRNA Binding. Our fluorescent dendrimers exhibited $\mathrm{pH}$-dependent aggregation, as revealed by using the Nile Red assay (Figure $2 \mathrm{a} / \mathrm{b}$ and Figure S4). ${ }^{61}$ For transfection dendrimers 1C/D1C and 1B/D1B with a lipidated core (red curves), we observed a transition from high aggregation above $\mathrm{pH} \mathrm{6,} \mathrm{corresponding} \mathrm{to} \mathrm{the} \mathrm{extracellular} \mathrm{medium,} \mathrm{to} \mathrm{a} \mathrm{low}$ aggregation below $\mathrm{pH} 5.5$ corresponding to the acidified endosome. A similar transition occurred with dendrimers 3C/ D3C and 3B/D3B with an oligoleucine core between $\mathrm{pH} 7$ and $\mathrm{pH} 6$ (orange curves). By contrast, negative control dendrimers $6 \mathrm{C} / 6 \mathrm{~B}$ (green curves) were not aggregated and 7C/7B (cyan curves) were aggregated across the entire $\mathrm{pH}$ range. While the fluorescence intensity of the coumarin label changed by less than $50 \%$ across the $\mathrm{pH}$ range, the BODIPY label was entirely quenched above $\mathrm{pH} 6$ in all cases except for the nonaggregated dendrimer $\mathbf{6 B}$ (green curve), reflecting autoquenching caused by aggregation. ${ }^{62-65}$

The coumarin label in transfecting dendrimers 1C, D1C, 3C, and D3C underwent a small blue shift between the nonaggregated state at $\mathrm{pH} 5.0$ and the aggregated state at $\mathrm{pH}$ $7.4\left(\lambda_{\max }=480 \rightarrow 474 \mathrm{~nm}\right.$, Figure $\left.2 \mathrm{c}\right)$. By comparison, the fluorescence of the nontransfecting nonaggregating dendrimer 

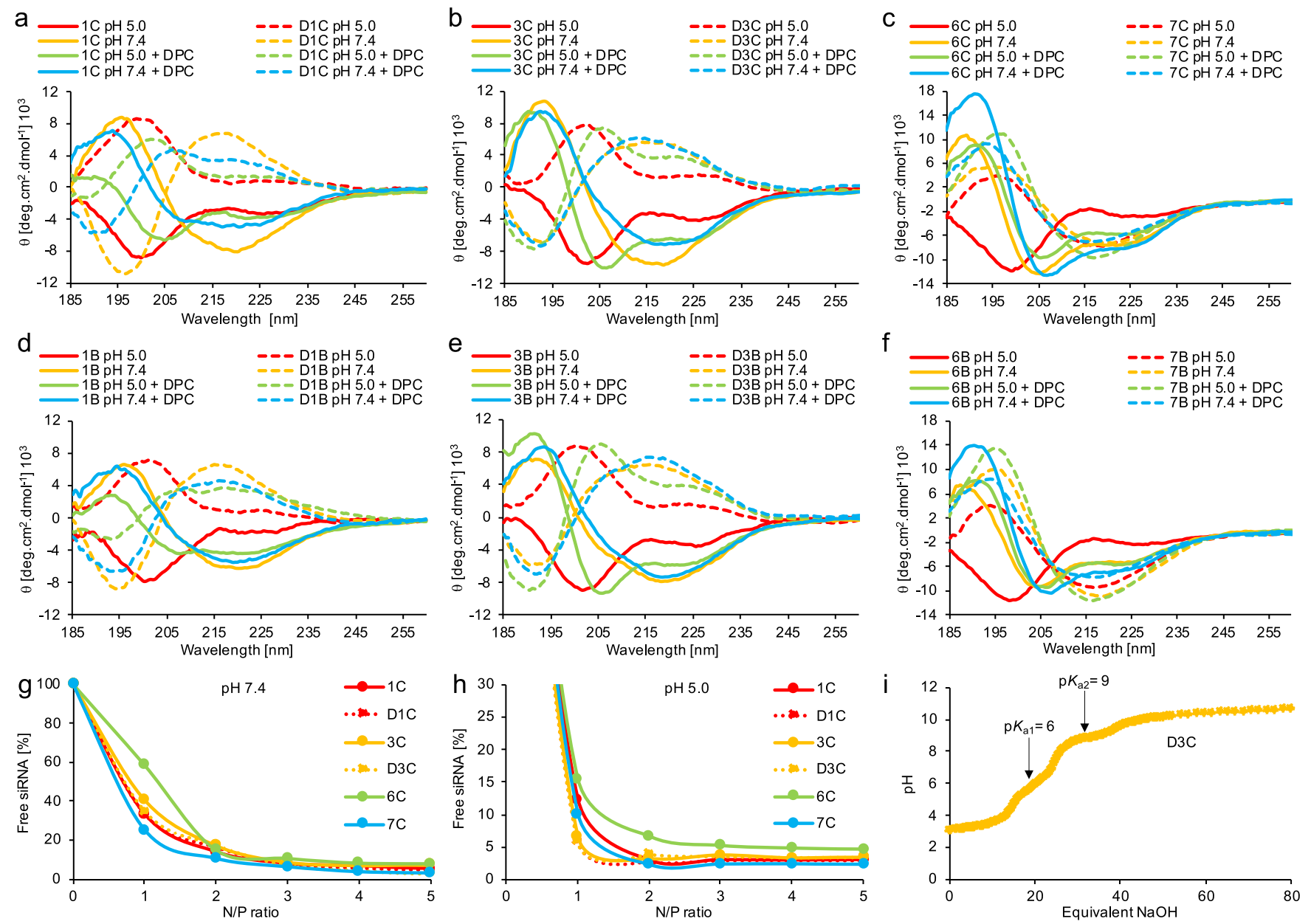

Figure 3. $\mathrm{pH}$ dependent secondary structure and siRNA binding of peptide dendrimers. $(\mathrm{a}-\mathrm{f})$ Conformation of transfection peptide dendrimers in solution at $\mathrm{pH} 5.0$ and $\mathrm{pH} 7.4$ and in the presence of DPC micelles. Circular dichroism spectra of coumarin $(\mathrm{a}-\mathrm{c})$ and BODIPY (d-f) peptide dendrimers $(100 \mu \mathrm{g} / \mathrm{mL})$ in $10 \mathrm{mM}$ phosphate buffer $(\mathrm{PB})$ at $\mathrm{pH} 5.0$ or $\mathrm{pH} 7.4$ in absence or presence of dodecylphosphocholine (DPC, $5 \mathrm{mM}$ ). (g) Free siRNA assay by intercalation of Quant-it microRNA in complexes of siRNA $(20 \mathrm{nM})$ and peptide dendrimers $(\mathrm{N} / \mathrm{P} 1-10,42-420 \mathrm{nM}$, $0.3-3 \mu \mathrm{g} / \mathrm{mL})$ as a function of the N/P ratio at $\mathrm{pH} 7.4$ in Quant-it microRNA buffer. Readings at N/P $=10$ were the same as at N/P $=5($ data not shown). (h) is the same as $(\mathrm{g})$ at $\mathrm{pH} 5.0$ in Quant-it microRNA buffer acidified with $10 \mathrm{mM}$ acetate buffer. Fluorescence normalized to siRNA alone was set as $100 \%$. All experiments were performed in triplicate. (i) Acid-based titration of D3C.

6C was constant and close to the lower value $\left(\lambda_{\max }=482 \mathrm{~nm}\right)$, and that of the nontransfecting aggregated dendrimer $7 \mathrm{C}$ was constant at the higher value $\left(\lambda_{\max }=474 \mathrm{~nm}\right)$. The difference in fluorescence of the BODIPY label in 1B, D1B, 3B, and D3B between $\mathrm{pH} 5.0$ and $\mathrm{pH} 7.4$ corresponded to a small red shift $\left(\lambda_{\max }=522 \rightarrow 535 \mathrm{~nm}\right.$, Figure $\left.2 \mathrm{~d}\right)$. In this case, the fluorescence of the nonaggregated nontransfecting dendrimer $6 \mathrm{~B}$ was constant at the lower value $\left(\lambda_{\max }=522 \mathrm{~nm}\right)$, while that of the nontransfecting aggregated dendrimer $7 \mathbf{B}$ behaved similarly to the transfecting dendrimers $\left(\lambda_{\max }=522 \rightarrow 535\right.$ $\mathrm{nm})$, in line with the fact that significant unquenching had already started around $\mathrm{pH}$ 5.5.

The observed blue and red shifts in coumarin and BODIPY fluorescence upon aggregation indicate the formation of fluorophores $\mathrm{H}$ - and J-aggregates ${ }^{66-70}$ and therefore close intermolecular interactions between peptide dendrimers in the aggregated state, which might be mediated by intermolecular $\beta$-sheets (see below) or by close contact between two dendrimers as recently documented in an X-ray crystal structure of a related peptide dendrimer. ${ }^{71}$

Circular dichroism (CD) spectra recorded at $\mathrm{pH} 7.4$ or at $\mathrm{pH} 5.0$ with or without $5 \mathrm{mM}$ dodecyl phosphocholine (DPC) as a membrane-like environment ${ }^{72,73}$ showed that the secondary structure content of our dendrimers changed with $\mathrm{pH}$ and aggregation state (Figure $3 \mathrm{a}-\mathrm{f}$ ). The $\mathrm{CD}$ traces of lipidated dendrimers 1C/D1C (Figure 3a) and 1B/D1B (Figure $3 \mathrm{~d}$ ) under the different conditions showed an isosbestic point indicating a transition between two states consisting of a $\beta$-sheet conformation in their aggregated state at $\mathrm{pH} 7.4$ (yellow lines, broad $\mathrm{max} / \mathrm{min}$ at $\lambda \sim 195-200 \mathrm{~nm}$ and single broad $\mathrm{min} / \mathrm{max}$ at $\lambda \sim 220 \mathrm{~nm}$ for L/D-peptides), which was slightly enhanced in the presence of DPC (cyan lines), to a partially $\alpha$-helical conformation at $\mathrm{pH} 5.0$ in the presence of DPC (green lines, sharp $\max / \mathrm{min}$ at $\lambda \sim 190-195$ $\mathrm{nm}$ double $\mathrm{min} / \mathrm{max}$ at $\lambda \sim 208$ and $222 \mathrm{~nm}$ for L/D-peptides) via a random coil at $\mathrm{pH} 5.0$ without DPC (red lines, broad $\mathrm{min} / \mathrm{max}$ at $\lambda \sim 200 \mathrm{~nm}$ for L/D-peptides). Dendrimers 3C/ D3C (Figure 3b) and 3B/D3B (Figure 3e) similarly transitioned from a predominantly $\beta$-sheet conformation at $\mathrm{pH} 7.4$ with or without DPC (yellow and cyan lines) to a random coil at $\mathrm{pH} 5.0$ (red lines) and finally an $\alpha$-helical conformation with DPC, although there was no clear isosbestic point. 

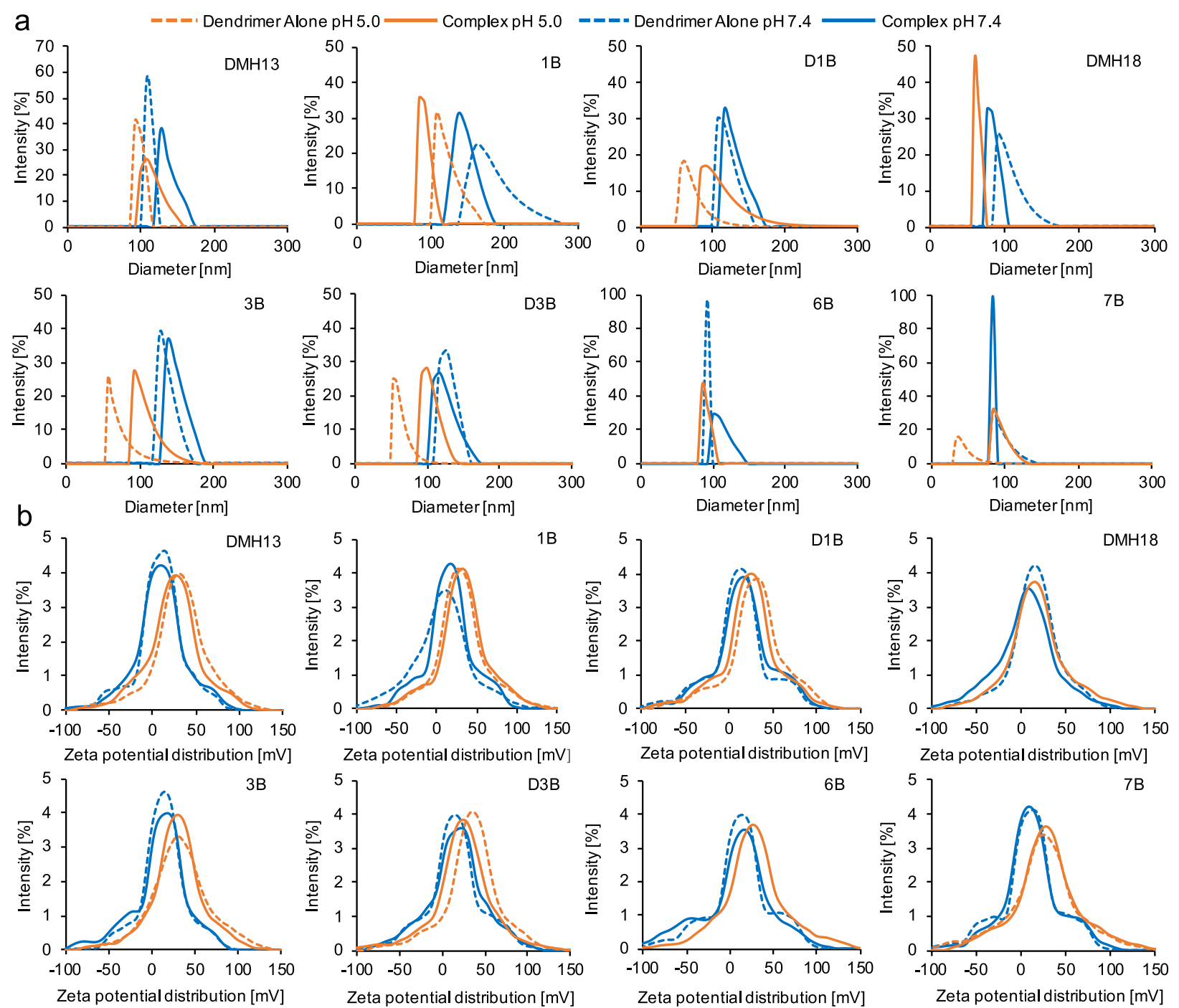

Figure 4. (a) Dynamic light scattering and (b) zeta potential of siRNA $(1.6 \mu \mathrm{M})$ and peptide dendrimers $(\mathrm{N} / \mathrm{P} 10,30.5-42 \mu \mathrm{M}, 232-287 \mu \mathrm{g} /$ $\mathrm{mL}$ ) alone or in complexes formed in PB at pH 5.0 and 7.4. All data shown have a polydispersity index (PDI) < 0.5. Curves are missing when no particles were detected.

The CD spectra of the nonaggregating and nontransfecting dendrimers 6C (full lines, Figure 3c) and 6B (full lines, Figure 3f) again showed an isosbestic point, with an $\alpha$-helical conformation at $\mathrm{pH} 7.4$ with (cyan lines) or without (yellow lines) DPC, as well as at $\mathrm{pH} 5.0$ with DPC (green lines), and a random coil at $\mathrm{pH} 5.0$ (red lines). Finally, the CD spectra of the nontransfecting dendrimers $7 \mathrm{C}$ (dashed lines, Figure 3c) and $7 \mathbf{B}$ (dashed lines, Figure $2 \mathrm{f}$ ), which are aggregated at all $\mathrm{pH}$ values and bind siRNA tightly, showed a very similar $\beta$ sheet containing conformation under all conditions. Overall, the CD spectra indicated a transition from a $\beta$-sheet conformation in the aggregated state to a random coil or $\alpha$ helical conformation in the nonaggregated state across all transfecting dendrimers.

We next measured siRNA binding for the coumarin-labeled series as a function of $\mathrm{pH}$ and $\mathrm{N} / \mathrm{P}$ ratio using the Quant-it microRNA assay. All dendrimers completely bound siRNA above $\mathrm{N} / \mathrm{P}=5$ at $\mathrm{pH} 7.4$ (Figure $3 \mathrm{~g}$ ) and above $\mathrm{N} / \mathrm{P}=2$ at $\mathrm{pH} 5.0$ (Figure $3 \mathrm{~h}$ ). The tightest binding was observed with inactive dendrimer $7 \mathrm{C}$ and the weakest binding with inactive dendrimer 6C. As demonstrated previously with nonlabeled dendrimers and verified here with D3C, amino termini underwent protonation at approximately $\mathrm{pH} \mathrm{6,} \mathrm{leading} \mathrm{to}$ eight additional positive charges per dendrimer upon acidification. This protonation explains the different stoichiometries of siRNA binding between $\mathrm{pH} 7.4$ and $\mathrm{pH} 5.0$ (Figure 3i). Furthermore, the correlation between $\beta$-sheet content and aggregation noted above suggests that aggregation is mediated by intermolecular $\beta$-sheet cross-links and is necessary for siRNA binding.

We further characterized the $\mathrm{pH}$ dependent aggregation of our dendrimers as siRNA complexes at $\mathrm{pH} 7.4$ or $\mathrm{pH} 5.0$ using dynamic light scattering for the case of the BODIPY dendrimers, because they showed the most interesting fluorescence modulation (DLS, N/P $=10$, Figure 4). ${ }^{74}$ The size distribution of siRNA complexes decreased from 80 to 150 $\mathrm{nm}$ at $\mathrm{pH} 7.4$ to $60-100 \mathrm{~nm}$ at $\mathrm{pH} 5.0$, while the zeta potential value distribution increased from 10 to $20 \mathrm{mV}$ at $\mathrm{pH} 7.4$ to 20-50 $\mathrm{mV}$ at $\mathrm{pH} 5.0$, reproducing our previous observations with DMH13 and DMH18. We interpret these changes as partial release of the dendrimer caused by protonation of the multiple N-termini leading to an increased number of positive charges on the dendrimer, forming more compact but also more stable nanoparticles at lower $\mathrm{pH}$. 

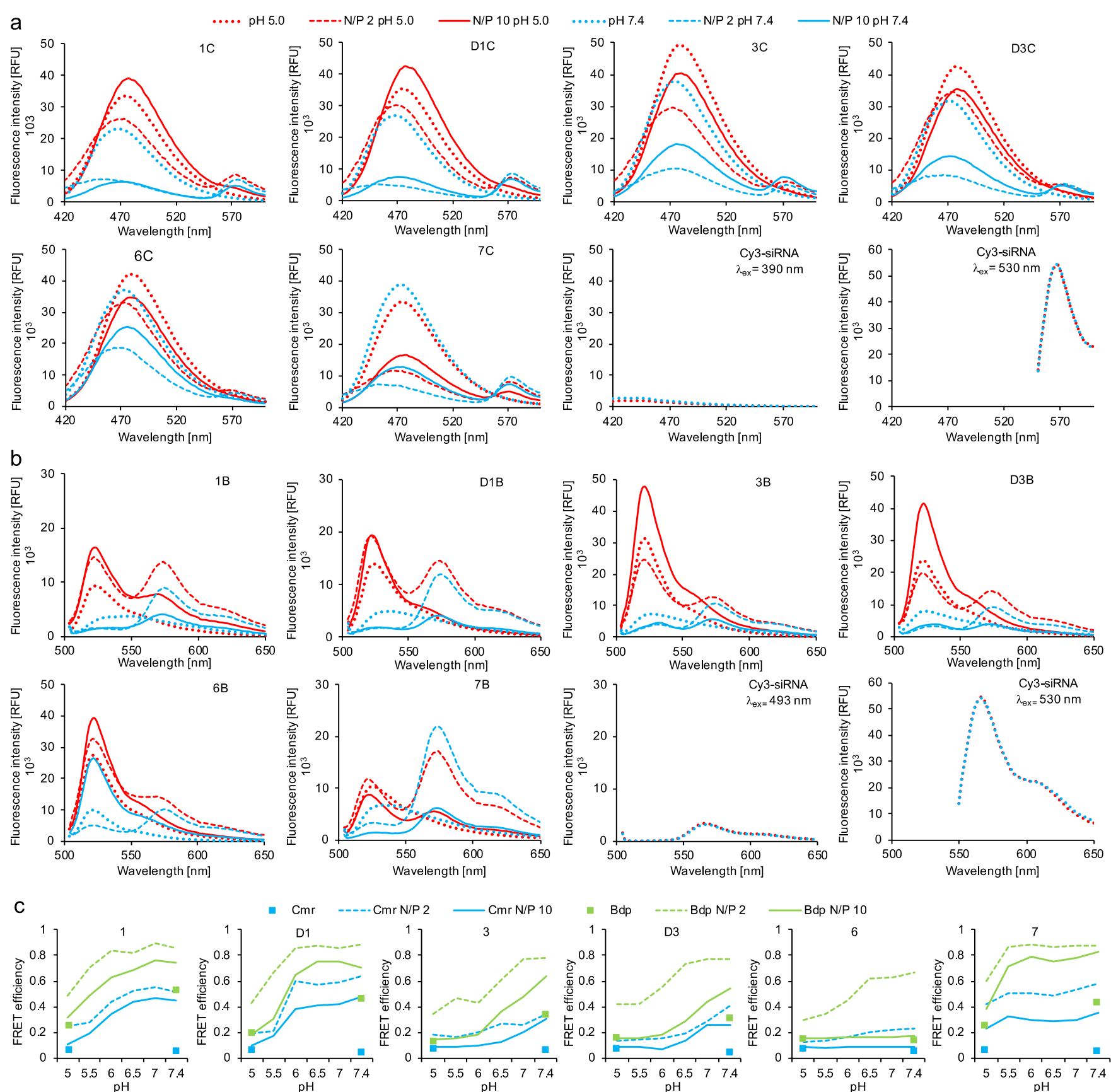

Figure 5. $\mathrm{pH}$ dependent complex dissociation and monomer release. Fluorescence scans of complex formed with Cy3-siRNA (100 nM) and (a) $\mathrm{Cmr}$ and (b) Bdp peptide dendrimers (N/P 2 or $10, \mu \mathrm{M}, 3$ or $15 \mu \mathrm{g} / \mathrm{mL})$ or peptide dendrimers alone $(15 \mu \mathrm{g} / \mathrm{mL})$ at $\mathrm{pH} 5.0-7.4$ with excitation wavelengths at $\lambda_{\mathrm{ex}}=390 \mathrm{~nm}$ for $\mathrm{Cmr}$ and at $\lambda_{\mathrm{ex}}=493 \mathrm{~nm}$ for Bdp. (c) FRET efficiency in complexes formed as above at pH 5.0-7.4 taken from scans at wavelength of $\lambda_{\text {donor }} / \lambda_{\text {acceptor }}=470 / 574 \mathrm{~nm}$ for Cmr and $\lambda_{\text {donor }} / \lambda_{\text {acceptor }}=520 / 574 \mathrm{~nm}$ for Bdp. Ratio of fluorescence intensity at the same wavelength for peptide dendrimers alone was added for comparison purposes. Fluorescence scans at $\mathrm{pH} 5.0-7.4$ in these conditions are present in Figure S5. RFU = Relative fluorescence unit.

The DLS data of the dendrimers alone showed that, depending on the particular dendrimer, their aggregates at $\mathrm{pH}$ 7.4 were either smaller (DMH13, 6B), similarly sized (D1B, 3B, D3B), or larger (1B, DMH18, 7B) than their siRNA complexes and had comparable zeta potential value distributions. At $\mathrm{pH} 5.0$, the free dendrimers all formed smaller nanoparticles than at $\mathrm{pH} 7.4$, or no aggregates at all (DMH18, 6B), in line with the Nile Red assay discussed above. In all cases, the zeta potential value distributions were similar to the
siRNA complexes indicating more stable nanoparticles at lower $\mathrm{pH}$.

Taken together, these experiments were consistent with our previous studies with DMH13, DMH18, and other nonlabeled analogs and showed that our fluorescence labeled dendrimers behaved similarly to their nonlabeled parents in terms of $\mathrm{pH}$ dependent aggregation, secondary structure, and siRNA binding properties, with comparable variations as a function of changes in hydrophobicity, positive charges, and chirality. 

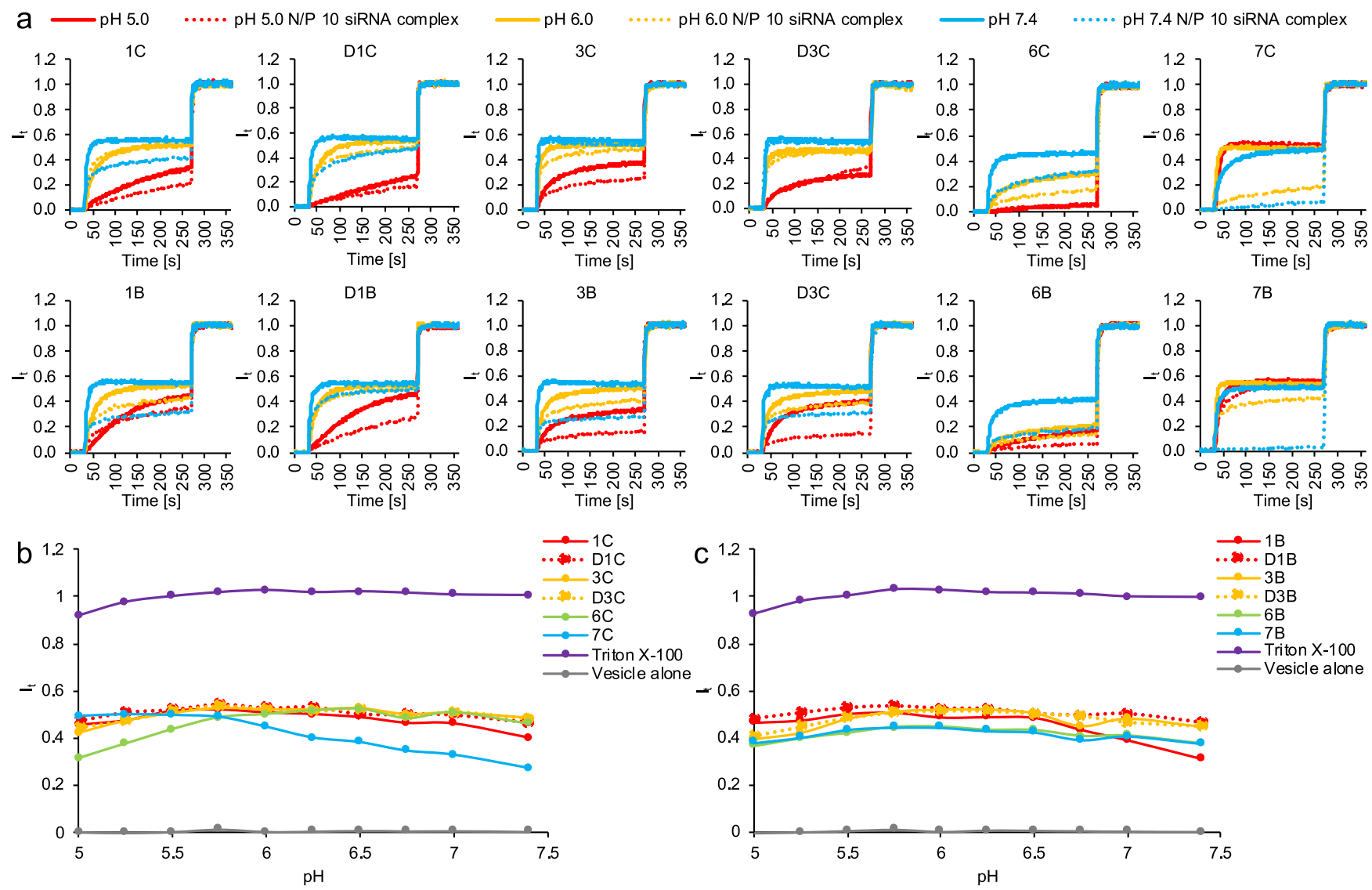

Figure 6. Evidence for membrane disruption at various $\mathrm{pH}$ values by transfection peptide dendrimers. (a) Sulforhodamine B leakage from phosphatidyl choline lipid vesicles suspended in buffer (125 $\mu \mathrm{M}$ EYPC, $625 \mu \mathrm{M} \mathrm{SRB}, 10 \mathrm{mM} \mathrm{PB}$; pH 5.0, 6.0, and 7.4). After $30 \mathrm{~s}$, peptide dendrimers $(7.5 \mu \mathrm{g} / \mathrm{mL})$ or complexes formed with siRNA $(50 \mathrm{nM})$ and peptide dendrimers $(\mathrm{N} / \mathrm{P} 10,1.05 \mu \mathrm{M}, 7.5 \mu \mathrm{g} / \mathrm{mL})$ were added to the lipid vesicle solution. After $270 \mathrm{~s}$, Triton X-100 (0.625\%) was added for full release of SRB and measured at $\lambda_{\mathrm{ex}}=565 \mathrm{~nm}$ and at $\lambda_{\mathrm{ex}}=586 \mathrm{~nm}$. Leakage properties of L2000 are present in Figure S6. (b) SRB leakage from EYPC vesicle with Cmr labeled peptide dendrimers (1.05 $\mu \mathrm{M}, 7.5 \mu \mathrm{g} /$ $\mathrm{mL}$ ) after $30 \mathrm{~min}$ incubation at $\mathrm{pH}$ 5.0-7.4. (c) is the same as (b) with Bdp labeled peptide dendrimers. $I_{\mathrm{t}}=$ ratio of fluorescence intensity.

FRET Studies. We next performed fluorescence resonance energy transfer (FRET) studies with Cy3-labeled siRNA to directly probe the proximity of siRNA-dendrimer interactions. The fluorescence of the Cy3-label occurred at $\lambda_{\mathrm{em}}=574 \mathrm{~nm}$ upon excitation at $\lambda_{\mathrm{ex}}=530 \mathrm{~nm}$ but was negligible when using the excitation wavelength of the coumarin $\left(\lambda_{\mathrm{ex}}=390 \mathrm{~nm}\right)$ or BODIPY $\left(\lambda_{\mathrm{ex}}=493 \mathrm{~nm}\right)$ label. These properties made it possible to monitor FRET and therefore a direct interaction between siRNA and dendrimer by recording Cy3 fluorescence at $\lambda_{\mathrm{em}}=574 \mathrm{~nm}$ by exciting at the excitation wavelength of the dendrimer labels.

The fluorescence of the coumarin-labeled transfection dendrimers 1C/D1C and 3C/D3C at pH $7.4\left(\lambda_{\text {ex }}=390\right.$ $\left.\mathrm{nm}, \quad \lambda_{\mathrm{em}}=470 \mathrm{~nm}\right)$ was very strongly reduced upon complexation with Cy3-siRNA at $\mathrm{N} / \mathrm{P}=2$ or $\mathrm{N} / \mathrm{P}=10$, producing at the same time a FRET emission of Cy3-siRNA at $\lambda_{\mathrm{em}}=574 \mathrm{~nm}$, indicating a close association between dendrimer and siRNA (Figure 5a, cyan curves). At pH 5.0 by contrast, siRNA complexation did not significantly reduce the intensity of dendrimer fluorescence for $1 \mathrm{C} / \mathrm{D} 1 \mathrm{C}$ and $3 \mathrm{C} /$ D3C $\left(\lambda_{\mathrm{em}}=470 \mathrm{~nm}\right)$, while the FRET effect to Cy3-siRNA was eliminated with $\mathrm{N} / \mathrm{P}=10$ but preserved at $\mathrm{N} / \mathrm{P}=2$, indicating that most but not all of the dendrimer was dissociated from siRNA at $\mathrm{pH} 5.0$ (Figure 5a, red curves). For the nontransfecting dendrimer 6C, Cy3-siRNA complexation did not induce any significant change in dendrimer fluorescence or FRET at both $\mathrm{pH}$ values, in line with its weak siRNA binding ability. For the nontransfecting dendrimer 7C, by contrast, Cy3-siRNA complexation caused a strong reduction in dendrimer fluorescence and significant FRET at both $\mathrm{pH} 7.4$ and $\mathrm{pH}$ 5.0, reflecting its tight siRNA binding across the entire $\mathrm{pH}$ range studied.

For the BODIPY labeled transfection dendrimers 1B/D1B and $3 \mathbf{B} / \mathbf{D} 3 \mathbf{B}$, a strong autoquenching occurred for all dendrimers at $\mathrm{pH} 7.4$ with or without bound siRNA, together with a FRET emission by bound Cy3-siRNA which was particularly strong at $\mathrm{N} / \mathrm{P}=2$, reflecting a close proximity between these dendrimers and Cy3-siRNA (Figure 5b, cyan curves). Autoquenching was strongly reduced for these dendrimers at $\mathrm{pH} 5.0$ indicating disaggregation. However, as for the coumarin labeled dendrimers discussed above, FRET to Cy3-siRNA remained strong at $\mathrm{N} / \mathrm{P}=2$, showing that some dendrimer remained bound to siRNA (Figure $5 b$, red curves). The nontransfecting dendrimer $6 \mathrm{~B}$ behaved similarly except for reduced autoquenching at $\mathrm{pH} 7.4$ and $\mathrm{N} / \mathrm{P}=10$ and $\mathrm{a}$ somewhat weaker FRET at $\mathrm{N} / \mathrm{P}=2$ at both $\mathrm{pH}$ values, reflecting its lower siRNA binding and aggregating ability. Finally, the nontransfecting dendrimer $\mathbf{7} \mathbf{B}$ showed strong autoquenching and FRET at both $\mathrm{pH}$ values, as expected from its tight siRNA binding ability.

We further determined the $\mathrm{pH}$ dependence of the FRET efficiency between dendrimer and siRNA for the coumarin 

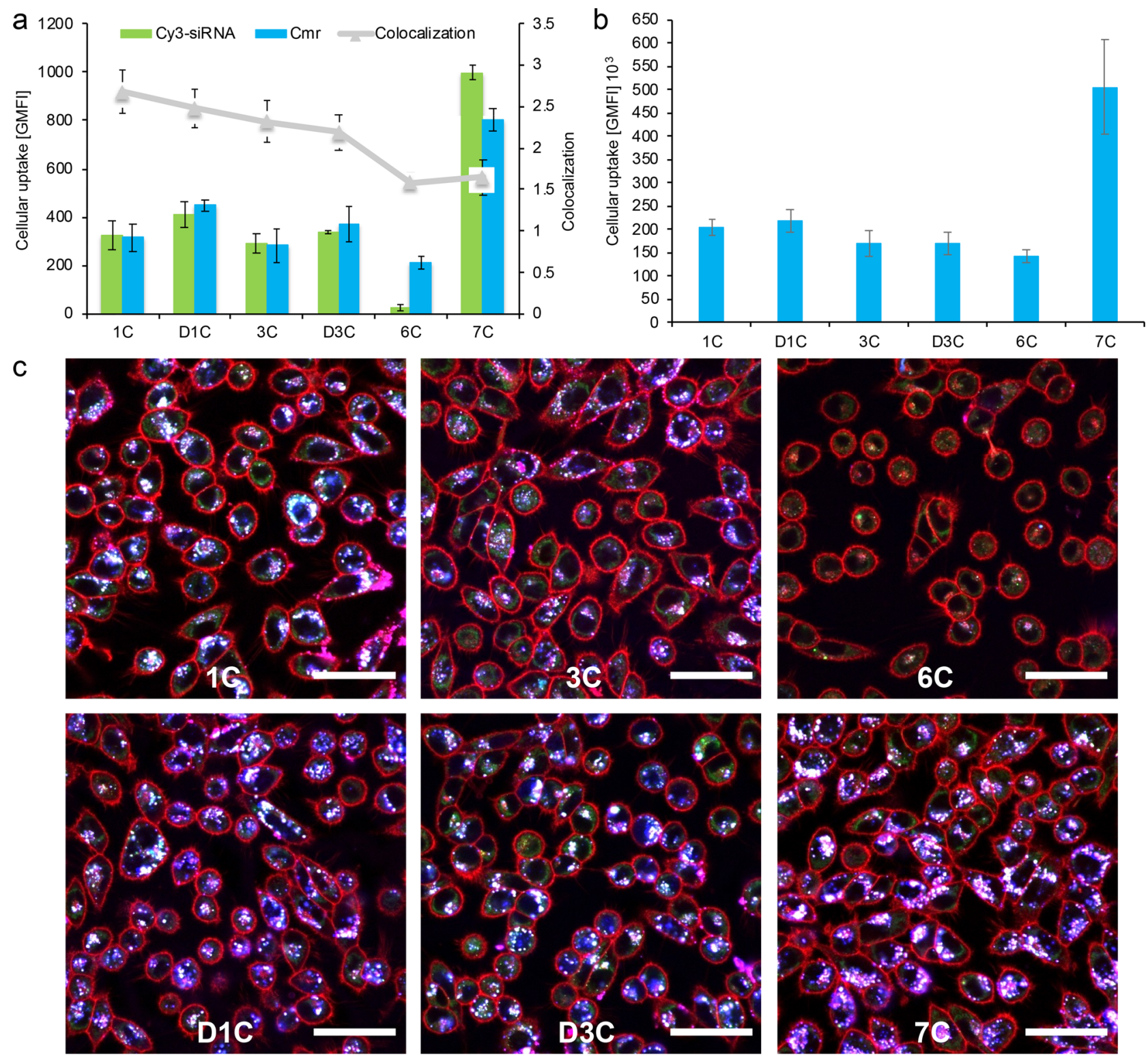

Figure 7. Cellular uptake and localization of Cy3-siRNA and Cmr-labeled peptide dendrimer. (a) Geo mean fluorescence intensity (GMFI) of internalized Cy3-siRNA (100 nM) and Cmr peptide dendrimers (N/P 10, $2.1 \mu \mathrm{M}, 15 \mu \mathrm{g} / \mathrm{mL})$ in HeLa cells after $4 \mathrm{~h}$ transfection. The gray line represents the colocalization of both dyes determined by the software (the higher the value the more colocalized). Error bars represent the standard deviation of two independent experiments, and all results are normalized to cell mask deep red (CMDR, Figure S9). (b) Internalization of the peptide dendrimers alone $(2.1 \mu \mathrm{M}, 15 \mu \mathrm{g} / \mathrm{mL}$ ) in HeLa cells after $4 \mathrm{~h}$ incubation. (c) Live cells confocal microscopy of Cy3-siRNA (green) and peptide dendrimers (blue) in HeLa cells. HeLa cells were incubated with Cy3-siRNA (100 nM) and peptide dendrimers (N/P 10, $2.1 \mu \mathrm{M}, 15 \mu \mathrm{g} /$ $\mathrm{mL}$ ) for $4 \mathrm{~h}$ in Opti-MEM. The plasma membrane was stained with Cell mask deep red. White scale bars represent $50 \mu \mathrm{m}$ (lens $\times 40 / 1.3)$. Nonoverlaid images are shown in Figure S8.

$\left(\lambda_{\text {donor }} / \lambda_{\text {acceptor }}=470 / 574 \mathrm{~nm}\right)$ and BODIPY $\left(\lambda_{\text {donor }} / \lambda_{\text {acceptor }}=\right.$ $520 / 574 \mathrm{~nm}$ ) between $\mathrm{pH} 7.4$ and $\mathrm{pH} 5.0$ (Figure 5c). This data illustrated the gradual decrease in close dendrimer siRNA interactions upon acidification for the eight transfection dendrimers (1C/1B, D1C/D1B, 3C/3B, D3C/D3B). The generally low level of association for the weakly binding, nontransfecting dendrimers $6 \mathrm{C} / 6 \mathrm{~B}$ and the almost $\mathrm{pH}$ independent tight association of siRNA with the tight binding, nontransfecting dendrimers $7 \mathrm{C} / 7 \mathrm{~B}$ were also evident in this $\mathrm{pH}$ profile.

The above FRET experiments were overall consistent with the aggregation studies discussed above and showed that dendrimers and siRNA interact in close proximity within the formed nanoparticles at $\mathrm{pH} \mathrm{7.4,} \mathrm{which} \mathrm{upon} \mathrm{acidification} \mathrm{to}$
$\mathrm{pH} 5.0$ release most of the dendrimer into solution while leaving some dendrimer closely complexed with siRNA.

Membrane Disruption. In our mechanistic model, the free dendrimer liberated from the dendrimer/siRNA nanoparticle upon acidification of the endosome facilitates endosome escape by destabilizing the endosomal membrane. We had previously shown by vesicle leakage assays that our transfection dendrimers can disrupt lipid vesicles consisting of zwitterionic egg yolk phosphatidyl choline (EYPC) loaded with fluorescein as reporter dye; however, these experiments were carried out at $\mathrm{pH}$ 7.4. To test their membrane disrupting activity under the acidic conditions of the endosome, we carried out these experiments at $\mathrm{pH} 7.4, \mathrm{pH} 6.0$, and $\mathrm{pH} 5.0$ using either the free dendrimers or their siRNA complexes at 
$\mathrm{N} / \mathrm{P}=10$. We loaded the vesicles with sulforhodamine $\mathrm{B}$ (SRB) ${ }^{75}$ a $\mathrm{pH}$-independent reporter dye whose fluorescence wavelengths $\left(\lambda_{\mathrm{ex}}=565 \mathrm{~nm}, \lambda_{\mathrm{em}}=586 \mathrm{~nm}\right)$ did not interfere with the fluorescent labels of our dendrimers.

All dendrimers had a strong membrane disruptive activity at $\mathrm{pH} 7.4$ (Figure 6a, cyan lines). This activity was significantly reduced upon siRNA complexation in all cases except $3 \mathrm{C}$ and D3C and was entirely suppressed for tight binding nontransfecting dendrimers $\mathbf{7 C}$ and $7 \mathbf{B}$ (Figure 6a, dashed cyan lines). At $\mathrm{pH}$ 6.0, the membrane disruptive activity was almost as strong for both free dendrimer and siRNA complexes in all cases except for the nontransfecting dendrimers $6 \mathrm{C} / 6 \mathrm{~B}$ and the siRNA complexed nontransfecting dendrimer 7C (Figure $6 \mathrm{a}$, orange lines). All transfection dendrimers retained their membrane disruptive activity upon further acidification to $\mathrm{pH}$ 5.0, although the nontransfecting dendrimers $6 \mathrm{C}$ and $6 \mathrm{~B}$ became almost completely inactive (Figure $6 \mathrm{a}$, red lines). However, extending the vesicle incubation time to $30 \mathrm{~min}$, which would be somewhat closer to the residence times of dendrimers during transfection, led to extensive vesicle leakage for all dendrimers across the entire $\mathrm{pH}$ range in both the coumarin labeled series (Figure $6 \mathrm{~b}$ ) and the BODIPY labeled series (Figure 6c).

Taken together, these data indicated that the 8 -fold protonation of dendrimer amino-termini and the accompanying change in secondary structure and aggregation state taking place upon acidification reduced but did not abolish the membrane disruptive activity of our dendrimers. Although EYPC vesicles are very simplified compared to endosomes, these experiments suggest that the dendrimers probably participate in endosomal membrane disruption as part of the overall transfection mechanism.

Fluorescence Imaging of Cellular Uptake of Dendrimer/siRNA Complexes. We previously showed that the nanoparticles formed upon siRNA complexation by our transfection dendrimers enter cells by endocytosis and eventually escape the endosome to release their cargo into the cytosol. Here, the availability of fluorescently labeled dendrimers allowed us to investigate if siRNA and dendrimers were colocalized during the transfection process. To investigate this point, we used the coumarin labeled series together with a fluorescence labeled Cy3-siRNA ${ }^{56}$ to track both reagents separately upon internalization of the dendrimer/siRNA complexes into HeLa cells.

Flow cytometry showed comparable uptake values for dendrimer and for siRNA across the different dendrimers, as expected from the fact that these reagents are internalized into cells as complexes (Figure 7a). The internalization levels were slightly higher for D1C and D3C compared to their Lenantiomers $\mathbf{1 C}$ and $3 \mathrm{C}$, in line with the stronger transfection efficiency of the D-enantiomers. The highest level of internalization occurred with the nontransfecting dendrimer 7C, which internalizes but does not release its siRNA cargo into the cells. On the other hand, dendrimer 6C, which only binds siRNA weakly, showed significantly lower internalization levels of Cy3-siRNA than of dendrimer, suggesting that some uncomplexed dendrimer also internalizes into cells in this case.

The dendrimers also internalized into cells without siRNA complexation, with relative levels corresponding to those of their siRNA complexes. This showed that internalization efficiency was primarily dictated by the dendrimer, which is not surprising if one considers that the dendrimer/siRNA complexes formed at $\mathrm{N} / \mathrm{P}=10$ contain an excess of dendrimer
(Figure 7b). However, there were no significant differences between L- and D-enantiomers in the case of 1C/D1C and 3C/ D3C. The absence of enantioselectivity in cellular uptake of the dendrimers without siRNA suggests that the process is not receptor mediated. We therefore believe that the small differences observed between $1 \mathrm{C} / 3 \mathrm{C}$ and their enantiomers D1C/D3C in cellular uptake of their siRNA complexes (Figure 7a) and their knock-down efficiency (Table 1) reflect a small level of diastereoselectivity in dendrimer-siRNA interactions influencing nanoparticle properties and siRNA release. We obtained similar results with $\mathrm{CHO}$ and HEK-293 cells (Figure S7).

Confocal images of transfected cells confirmed the flow cytometry data in terms of the amounts of cellular uptake (Figure 7c, Figure S8). Dendrimers and siRNA were mostly colocalized in punctuate patterns attributable to endosomes and lysosomes, with only very limited spread of fluorescence in the cytosol, in line with our previous observation with fluorescent siRNA and unlabeled dendrimers, an effect which has also been reported with other transfection reagents. ${ }^{76-80}$ Thus, although we did not observe any significant separation of dendrimer and siRNA fluorescence in these images, the level of fluorescence in the cytosol was generally too low to detect a possible separation of dendrimers from siRNA after endosome escape. We made similar observation in $\mathrm{CHO}$ and HEK-293 cells (Figures S9 and S10).

\section{CONCLUSION}

Here, we identified coumarin-labeled siRNA transfection dendrimers D1C/D3C and BODIPY-labeled dendrimers D1B/D3B as analogs of the previously reported transfection dendrimers DMH13/DMH18. Detailed investigations including nontransfecting dendrimers 6C/6B (weak siRNA binding) and $7 \mathrm{C} / 7 \mathrm{~B}$ (excessive siRNA binding) showed that these fluorescently labeled dendrimers behave similarly to their nonlabeled parents in terms of $\mathrm{pH}$ dependent aggregation, secondary structure content, and siRNA binding.

We then exploited dendrimer fluorescence to perform FRET studies, which showed that the dendrimers are in close proximity to siRNA within the nanoparticles formed at $\mathrm{pH} 7.4$ but are then mostly released into solution upon acidification to $\mathrm{pH}$ 5.0, modeling the conditions within the endosome. Vesicle leakage assays showed that the liberated dendrimer can disrupt model membranes at $\mathrm{pH} 5.0$ almost as well as at $\mathrm{pH} 7.4$, suggesting that the dendrimers participate in endosome escape by permeabilizing the endosomal membrane. Finally, we tracked siRNA transfection by confocal microscopy, which showed that the dendrimers colocalize with siRNA within the cells throughout the transfection process. Additional mechanistic studies regarding the internalization mechanism of our fluorescent transfection dendrimers might be possible as recently reported for siRNA delivery nanoparticles derived from cell penetrating peptides. ${ }^{81}$

While the present studies with fluorescently labeled peptide dendrimers provided novel insights into the mechanism of siRNA complexation and transfection, they also highlight that siRNA transfection by our peptide dendrimers is compatible with a variety of hydrophobic cores as long as the dendrimer branches are kept constant, suggesting a simple design strategy for nanoparticle forming peptide dendrimers, and a broad optimization potential for transfection applications. Nevertheless, the best system in terms of transfection efficiency across all fluorescent and nonfluorescent peptide dendrimers 
studied thus far is the amino-acid-only dendrimer DMH18 due to its ease of synthesis, low toxicity, and high transfection efficiency across different cell lines.

\section{METHODS}

Synthesis and characterization of peptide dendrimers, all assays and measurements are described in the Supporting Information.

\section{ASSOCIATED CONTENT}

\section{(s) Supporting Information}

The Supporting Information is available free of charge at https://pubs.acs.org/doi/10.1021/acs.bioconjchem.0c00231.

Details of synthesis and characterization of peptide dendrimers and all assays and measurements (PDF) List of peptide dendrimer structures as SMILES (XLSX)

\section{AUTHOR INFORMATION}

\section{Corresponding Author}

Jean-Louis Reymond - Department of Chemistry and Biochemistry, University of Bern, 3012 Bern, Switzerland; (ㄱ) orcid.org/0000-0003-2724-2942; Email: jeanlouis.reymond@dcb.unibe.ch

\section{Authors \\ Marc Heitz - Department of Chemistry and Biochemistry, University of Bern, 3012 Bern, Switzerland; 이이.org/ 0000-0001-7694-7805 \\ Susanna Zamolo - Department of Chemistry and Biochemistry, University of Bern, 3012 Bern, Switzerland \\ Sacha Javor - Department of Chemistry and Biochemistry, University of Bern, 3012 Bern, Switzerland}

Complete contact information is available at:

https://pubs.acs.org/10.1021/acs.bioconjchem.0c00231

\section{Notes}

The authors declare no competing financial interest.

\section{ACKNOWLEDGMENTS}

This work was supported financially by the Swiss National Science Foundation, Grant no. 200020_178998.

\section{REFERENCES}

(1) Yin, H., Kanasty, R. L., Eltoukhy, A. A., Vegas, A. J., Dorkin, J. R., and Anderson, D. G. (2014) Non-Viral Vectors for Gene-Based Therapy. Nat. Rev. Genet. 15 (8), 541-555.

(2) Zuckerman, J. E., and Davis, M. E. (2015) Clinical Experiences with Systemically Administered SiRNA-Based Therapeutics in Cancer. Nat. Rev. Drug Discovery 14 (12), 843-856.

(3) Ozcan, G., Ozpolat, B., Coleman, R. L., Sood, A. K., and LopezBerestein, G. (2015) Preclinical and Clinical Development of SiRNABased Therapeutics. Adv. Drug Delivery Rev. 87, 108-119.

(4) Chen, J., Guo, Z., Tian, H., and Chen, X. (2016) Production and Clinical Development of Nanoparticles for Gene Delivery. Mol. Ther.Methods Clin. Dev. 3, 16023.

(5) Khvorova, A., and Watts, J. K. (2017) The Chemical Evolution of Oligonucleotide Therapies of Clinical Utility. Nat. Biotechnol. 35 (3), 238-248.

(6) Kanasty, R., Dorkin, J. R., Vegas, A., and Anderson, D. G. (2013) Delivery Materials for SiRNA Therapeutics. Nat. Mater. 12 (11), 967-977.

(7) Lächelt, U., and Wagner, E. (2015) Nucleic Acid Therapeutics Using Polyplexes: A Journey of 50 Years (and Beyond). Chem. Rev. 115 (19), 11043-11078.
(8) Wang, H.-X., Li, M., Lee, C. M., Chakraborty, S., Kim, H.-W., Bao, G., and Leong, K. W. (2017) CRISPR/Cas9-Based Genome Editing for Disease Modeling and Therapy: Challenges and Opportunities for Nonviral Delivery. Chem. Rev. 117 (15), 98749906.

(9) Kim, B., Park, J., and Sailor, M. J. (2019) Rekindling RNAi Therapy: Materials Design Requirements for In Vivo SiRNA Delivery. Adv. Mater. 31 (49), 1903637.

(10) Zhi, D., Zhang, S., Cui, S., Zhao, Y., Wang, Y., and Zhao, D. (2013) The Headgroup Evolution of Cationic Lipids for Gene Delivery. Bioconjugate Chem. 24 (4), 487-519.

(11) Hersey, J. S., LaManna, C. M., Lusic, H., and Grinstaff, M. W. (2016) Stimuli Responsive Charge-Switchable Lipids: Capture and Release of Nucleic Acids. Chem. Phys. Lipids 196, 52-60.

(12) Gujrati, M., Vaidya, A., and Lu, Z.-R. (2016) Multifunctional PH-Sensitive Amino Lipids for SiRNA Delivery. Bioconjugate Chem. 27 (1), 19-35.

(13) Rietwyk, S., and Peer, D. (2017) Next-Generation Lipids in RNA Interference Therapeutics. ACS Nano 11 (8), 7572-7586.

(14) Buck, J., Grossen, P., Cullis, P. R., Huwyler, J., and Witzigmann, D. (2019) Lipid-Based DNA Therapeutics: Hallmarks of Non-Viral Gene Delivery. ACS Nano 13 (4), 3754-3782.

(15) Boussif, O., Lezoualc'h, F., Zanta, M. A., Mergny, M. D., Scherman, D., Demeneix, B., and Behr, J. P. (1995) A Versatile Vector for Gene and Oligonucleotide Transfer into Cells in Culture and in Vivo: Polyethylenimine. Proc. Natl. Acad. Sci. U. S. A. 92 (16), 72977301.

(16) Van Bruggen, C., Hexum, J. K., Tan, Z., Dalal, R. J., and Reineke, T. M. (2019) Nonviral Gene Delivery with Cationic Glycopolymers. Acc. Chem. Res., 1347-1358.

(17) Peeler, D. J., Sellers, D. L., and Pun, S. H. (2019) PH-Sensitive Polymers as Dynamic Mediators of Barriers to Nucleic Acid Delivery. Bioconjugate Chem. 30 (2), 350-365.

(18) Chen, J., Wang, K., Wu, J., Tian, H., and Chen, X. (2019) Polycations for Gene Delivery: Dilemmas and Solutions. Bioconjugate Chem. 30 (2), 338-349.

(19) Peng, L., and Wagner, E. (2019) Polymeric Carriers for Nucleic Acid Delivery: Current Designs and Future Directions. Biomacromolecules 20 (10), 3613-3626.

(20) Yang, D.-C., Eldredge, A. C., Hickey, J. C., Muradyan, H., and Guan, Z. (2020) Multivalent Peptide-Functionalized Bioreducible Polymers for Cellular Delivery of Various RNAs. Biomacromolecules $21,1613-1624$.

(21) Iqbal, S., Blenner, M., Alexander-Bryant, A., and Larsen, J. (2020) Polymersomes for Therapeutic Delivery of Protein and Nucleic Acid Macromolecules: From Design to Therapeutic Applications. Biomacromolecules 21, 1327-1350.

(22) Yang, J., Zhang, Q., Chang, H., and Cheng, Y. (2015) SurfaceEngineered Dendrimers in Gene Delivery. Chem. Rev. 115 (11), 5274-5300.

(23) Zeng, H., Johnson, M. E., Oldenhuis, N. J., Tiambeng, T. N., and Guan, Z. (2015) Structure-Based Design of Dendritic Peptide Bolaamphiphiles for SiRNA Delivery. ACS Cent. Sci. 1 (6), 303-312.

(24) $\mathrm{Hu}, \mathrm{J} ., \mathrm{Hu}, \mathrm{K}$., and Cheng, Y. (2016) Tailoring the Dendrimer Core for Efficient Gene Delivery. Acta Biomater. 35, 1-11.

(25) Tambe, V., Thakkar, S., Raval, N., Sharma, D., Kalia, K., and Tekade, R. K. (2017) Surface Engineered Dendrimers in SiRNA Delivery and Gene Silencing. Curr. Pharm. Des. 23 (20), 2952-2975.

(26) Dong, Y., Yu, T., Ding, L., Laurini, E., Huang, Y., Zhang, M., Weng, Y., Lin, S., Chen, P., Marson, D., et al. (2018) A Dual Targeting Dendrimer-Mediated SiRNA Delivery System for Effective Gene Silencing in Cancer Therapy. J. Am. Chem. Soc. 140 (47), 16264-16274.

(27) Sapra, R., Verma, R. P., Maurya, G. P., Dhawan, S., Babu, J., and Haridas, V. (2019) Designer Peptide and Protein Dendrimers: A Cross-Sectional Analysis. Chem. Rev. 119 (21), 11391-11441.

(28) Ojea-Jiménez, I., Tort, O., Lorenzo, J., and Puntes, V. F. (2012) Engineered Nonviral Nanocarriers for Intracellular Gene Delivery Applications. Biomed. Mater. 7 (5), 054106. 
(29) Loh, X. J., Lee, T.-C., Dou, Q., and Deen, G. R. (2016) Utilising Inorganic Nanocarriers for Gene Delivery. Biomater. Sci. 4 (1), 70-86.

(30) Lai, W.-F., Rogach, A. L., and Wong, W.-T. (2017) Molecular Design of Upconversion Nanoparticles for Gene Delivery. Chem. Sci. 8 (11), 7339-7358.

(31) Zhou, Y., Quan, G., Wu, Q., Zhang, X., Niu, B., Wu, B., Huang, Y., Pan, X., and Wu, C. (2018) Mesoporous Silica Nanoparticles for Drug and Gene Delivery. Acta Pharm. Sin. $B$ 8 (2), 165-177.

(32) Lin, G., Li, L., Panwar, N., Wang, J., Tjin, S. C., Wang, X., and Yong, K.-T. (2018) Non-Viral Gene Therapy Using Multifunctional Nanoparticles: Status, Challenges, and Opportunities. Coord. Chem. Rev. 374, 133-152.

(33) Darbre, T., and Reymond, J.-L. (2006) Peptide Dendrimers as Artificial Enzymes, Receptors, and Drug-Delivery Agents. Acc. Chem. Res. 39 (12), 925-934.

(34) Reymond, J.-L., and Darbre, T. (2012) Peptide and Glycopeptide Dendrimer Apple Trees as Enzyme Models and for Biomedical Applications. Org. Biomol. Chem. 10 (8), 1483-1492.

(35) Reymond, J. L., Bergmann, M., and Darbre, T. (2013) Glycopeptide Dendrimers as Pseudomonas Aeruginosa Biofilm Inhibitors. Chem. Soc. Rev. 42 (11), 4814-4822.

(36) Kwok, A., Eggimann, G. A., Reymond, J.-L., Darbre, T., and Hollfelder, F. (2013) Peptide Dendrimer/Lipid Hybrid Systems Are Efficient DNA Transfection Reagents: Structure-Activity Relationships Highlight the Role of Charge Distribution Across Dendrimer Generations. ACS Nano 7 (5), 4668-4682.

(37) Kwok, A., Eggimann, G. A., Heitz, M., Reymond, J.-L., Hollfelder, F., and Darbre, T. (2016) Efficient Transfection of SiRNA by Peptide Dendrimer-Lipid Conjugates. ChemBioChem 17 (23), $2223-2229$.

(38) Heitz, M., Kwok, A., Eggimann, G. A., Hollfelder, F., Darbre, T., and Reymond, J.-L. (2017) Peptide Dendrimer-Lipid Conjugates as DNA and SiRNA Transfection Reagents: Role of Charge Distribution Across Generations. Chimia 71 (4), 220-225.

(39) Jing, X., Foged, C., Martin-Bertelsen, B., Yaghmur, A., Knapp, K. M., Malmsten, M., Franzyk, H., and Nielsen, H. M. (2016) Delivery of SiRNA Complexed with Palmitoylated $\alpha$-Peptide/ $\beta$ Peptoid Cell-Penetrating Peptidomimetics: Membrane Interaction and Structural Characterization of a Lipid-Based Nanocarrier System. Mol. Pharmaceutics 13 (6), 1739-1749.

(40) Porosk, L., Arukuusk, P., Põhako, K., Kurrikoff, K., Kiisholts, K., Padari, K., Pooga, M., and Langel, Ü. (2019) Enhancement of SiRNA Transfection by the Optimization of Fatty Acid Length and Histidine Content in the CPP. Biomater. Sci. 7 (10), 4363-4374.

(41) Kang, Z., Meng, Q., and Liu, K. (2019) Peptide-Based Gene Delivery Vectors. J. Mater. Chem. B 7 (11), 1824-1841.

(42) Heitz, M., Javor, S., Darbre, T., and Reymond, J.-L. (2019) Stereoselective PH Responsive Peptide Dendrimers for SiRNA Transfection. Bioconjugate Chem. 30 (8), 2165-2182.

(43) Järve, A., Müller, J., Kim, I.-H., Rohr, K., MacLean, C., Fricker, G., Massing, U., Eberle, F., Dalpke, A., Fischer, R., et al. (2007) Surveillance of SiRNA Integrity by FRET Imaging. Nucleic Acids Res. 35 (18), No. e124.

(44) Alabi, C. A., Love, K. T., Sahay, G., Stutzman, T., Young, W. T., Langer, R., and Anderson, D. G. (2012) FRET-Labeled SiRNA Probes for Tracking Assembly and Disassembly of SiRNA Nanocomplexes. ACS Nano 6 (7), 6133-6141.

(45) Alabi, C. A., Sahay, G., Langer, R., and Anderson, D. G. (2013) Development of SiRNA-Probes for Studying Intracellular Trafficking of SiRNA Nanoparticles. Int. Biol. 5 (1), 224-230.

(46) Holzhauser, C., Liebl, R., Goepferich, A., Wagenknecht, H.-A., and Breunig, M. (2013) RNA "Traffic Lights": An Analytical Tool to Monitor SiRNA Integrity. ACS Chem. Biol. 8 (5), 890-894.

(47) Krieg, B., Hirsch, M., Scholz, E., Nuhn, L., Tabujew, I., Bauer, H., Decker, S., Khobta, A., Schmidt, M., Tremel, W., et al. (2015) New Techniques to Assess In Vitro Release of SiRNA from Nanoscale Polyplexes. Pharm. Res. 32 (6), 1957-1974.
(48) Hirsch, M., and Helm, M. (2015) Live Cell Imaging of Duplex SiRNA Intracellular Trafficking. Nucleic Acids Res. 43 (9), 4650-4660.

(49) Ahmed, N., De Graaf, J. F., Ahmed, N., Foss, D. V., Delcorde, J., Schultz, P. G., and Pezacki, J. P. (2018) Visualization of the Delivery and Release of Small RNAs Using Genetic Code Expansion and Unnatural RNA-Binding Proteins. Bioconjugate Chem. 29 (12), 3982-3986.

(50) Kang, H., DeLong, R., Fisher, M. H., and Juliano, R. L. (2005) Tat-Conjugated PAMAM Dendrimers as Delivery Agents for Antisense and SiRNA Oligonucleotides. Pharm. Res. 22 (12), 2099-2106.

(51) Serramía, M. J., Álvarez, S., Fuentes-Paniagua, E., Clemente, M. I., Sánchez-Nieves, J., Gómez, R., de la Mata, J., and MuñozFernández, M. Á. (2015) In Vivo Delivery of SiRNA to the Brain by Carbosilane Dendrimer. J. Controlled Release 200, 60-70.

(52) Li, Y., Wang, X., Zhang, Y., and Nie, G. (2020) Recent Advances in Nanomaterials with Inherent Optical and Magnetic Properties for Bioimaging and Imaging-Guided Nucleic Acid Therapy. Bioconjugate Chem. 31, 1234.

(53) Lamichhane, T. N., Jeyaram, A., Patel, D. B., Parajuli, B., Livingston, N. K., Arumugasaamy, N., Schardt, J. S., and Jay, S. M. (2016) Oncogene Knockdown via Active Loading of Small RNAs into Extracellular Vesicles by Sonication. Cell. Mol. Bioeng. 9 (3), 315-324.

(54) Yoshitake, M., Nohta, H., Sejima, N., Todoroki, K., Yoshida, H., and Yamaguchi, M. (2011) Selective Determination of Cysteines through Precolumn Double-Labeling and Liquid Chromatography Followed by Detection of Intramolecular FRET. Anal. Bioanal. Chem. 399 (4), 1665-1675.

(55) Lam, J. K. W., Liang, W., Lan, Y., Chaudhuri, P., Chow, M. Y. T., Witt, K., Kudsiova, L., and Mason, A. J. (2012) Effective Endogenous Gene Silencing Mediated by PH Responsive Peptides Proceeds via Multiple Pathways. J. Controlled Release 158 (2), 293303.

(56) Xu, W., Pan, R., Zhao, D., Chu, D., Wu, Y., Wang, R., Chen, B., Ding, Y., Sadatmousavi, P., Yuan, Y., and Chen, P. (2015) Design and Evaluation of Endosomolytic Biocompatible Peptides as Carriers for SiRNA Delivery. Mol. Pharmaceutics 12 (1), 56-65.

(57) Kolli, S., Wong, S.-P., Harbottle, R., Johnston, B., Thanou, M., and Miller, A. D. (2013) PH-Triggered Nanoparticle Mediated Delivery of SiRNA to Liver Cells in Vitro and in Vivo. Bioconjugate Chem. 24 (3), 314-332.

(58) Zhang, X.-X., LaManna, C. M., Kohman, R. E., McIntosh, T. J., Han, X., and Grinstaff, M. W. (2013) Lipid-Mediated DNA and SiRNA Transfection Efficiency Depends on Peptide Headgroup. Soft Matter 9 (17), 4472-4479.

(59) Lu, H.-H., Huang, C.-H., Shiue, T.-Y., Wang, F.-S., Chang, K.K., Chen, Y., and Peng, C.-H. (2019) Highly Efficient Gene Release in Spatiotemporal Precision Approached by Light and PH Dual Responsive Copolymers. Chem. Sci. 10 (1), 284-292.

(60) Peterson, J. A., Fischer, L. J., Gehrmann, E. J., Shrestha, P., Yuan, D., Wijesooriya, C. S., Smith, E. A., and Winter, A. H. (2020) Direct Photorelease of Alcohols from Boron-Alkylated BODIPY Photocages. J. Org. Chem. 85, 5712-5717.

(61) Mynar, J. L., Goodwin, A. P., Cohen, J. A., Ma, Y., Fleming, G. R., and Fréchet, J. M. J. (2007) Two-Photon Degradable Supramolecular Assemblies of Linear-Dendritic Copolymers. Chem. Commun. 20, 2081-2082.

(62) Johnson, I. D., Kang, H. C., and Haugland, R. P. (1991) Fluorescent Membrane Probes Incorporating Dipyrrometheneboron Difluoride Fluorophores. Anal. Biochem. 198 (2), 228-237.

(63) Karolin, J., Johansson, L. B.-A., Strandberg, L., and Ny, T. (1994) Fluorescence and Absorption Spectroscopic Properties of Dipyrrometheneboron Difluoride (BODIPY) Derivatives in Liquids, Lipid Membranes, and Proteins. J. Am. Chem. Soc. 116 (17), 78017806.

(64) Bergström, F., Mikhalyov, I., Hägglöf, P., Wortmann, R., Ny, T., and Johansson, L. B.-Å. (2002) Dimers of Dipyrrometheneboron Difluoride (BODIPY) with Light Spectroscopic Applications in Chemistry and Biology. J. Am. Chem. Soc. 124 (2), 196-204. 
(65) Tleugabulova, D., Zhang, Z., and Brennan, J. D. (2002) Characterization of Bodipy Dimers Formed in a Molecularly Confined Environment. J. Phys. Chem. B 106 (51), 13133-13138.

(66) Nepomnyashchii, A. B., Bröring, M., Ahrens, J., and Bard, A. J. (2011) Synthesis, Photophysical, Electrochemical, and Electrogenerated Chemiluminescence Studies. Multiple Sequential Electron Transfers in BODIPY Monomers, Dimers, Trimers, and Polymer. J. Am. Chem. Soc. 133 (22), 8633-8645.

(67) Verma, P., and Pal, H. (2012) Intriguing H-Aggregate and HDimer Formation of Coumarin-481 Dye in Aqueous Solution As Evidenced from Photophysical Studies. J. Phys. Chem. A 116 (18), $4473-4484$

(68) Luby, B. M., Charron, D. M., MacLaughlin, C. M., and Zheng, G. (2017) Activatable Fluorescence: From Small Molecule to Nanoparticle. Adv. Drug Delivery Rev. 113, 97-121.

(69) Qi, J., Hu, X., Dong, X., Lu, Y., Lu, H., Zhao, W., and Wu, W. (2019) Towards More Accurate Bioimaging of Drug Nanocarriers: Turning Aggregation-Caused Quenching into a Useful Tool. Adv. Drug Delivery Rev. 143, 206-225.

(70) Liu, Z., Jiang, Z., Yan, M., and Wang, X. (2019) Recent Progress of BODIPY Dyes With Aggregation-Induced Emission. Front. Chem. 7, 712.

(71) Baeriswyl, S., Javor, S., Stocker, A., Darbre, T., and Reymond, J.-L. (2019) X-Ray Crystal Structure of a Second-Generation Peptide Dendrimer in Complex with Pseudomonas Aeruginosa Lectin LecB. Helv. Chim. Acta 102, e1900178.

(72) Di Bonaventura, I., Baeriswyl, S., Capecchi, A., Gan, B.-H., Jin, X., Siriwardena, T. N., He, R., Köhler, T., Pompilio, A., Di Bonaventura, G., et al. (2018) An Antimicrobial Bicyclic Peptide from Chemical Space against Multidrug Resistant Gram-Negative Bacteria. Chem. Commun. 54 (40), 5130-5133.

(73) Kim, J., Jacob, B., Jang, M., Kwak, C., Lee, Y., Son, K., Lee, S., Jung, I. D., Jeong, M. S., Kwon, S.-H., et al. (2019) Development of a Novel Short 12-Meric Papiliocin-Derived Peptide That Is Effective against Gram-Negative Sepsis. Sci. Rep. 9 (1), 3817.

(74) Bhattacharjee, S. (2016) DLS and Zeta Potential - What They Are and What They Are Not? J. Controlled Release 235, 337-351.

(75) Boyken, S. E., Benhaim, M. A., Busch, F., Jia, M., Bick, M. J., Choi, H., Klima, J. C., Chen, Z., Walkey, C., Mileant, A., et al. (2019) De Novo Design of Tunable, PH-Driven Conformational Changes. Science 364 (6441), 658-664.

(76) Gilleron, J., Querbes, W., Zeigerer, A., Borodovsky, A., Marsico, G., Schubert, U., Manygoats, K., Seifert, S., Andree, C., Stöter, M., Epstein-Barash, H., Zhang, L., Koteliansky, V., Fitzgerald, K., Fava, E., Bickle, M., Kalaidzidis, Y., Akinc, A., Maier, M., and Zerial, M. (2013) Image-Based Analysis of Lipid Nanoparticle-Mediated SiRNA Delivery, Intracellular Trafficking and Endosomal Escape. Nat. Biotechnol. 31 (7), 638-646.

(77) Wittrup, A., Ai, A., Liu, X., Hamar, P., Trifonova, R., Charisse, K., Manoharan, M., Kirchhausen, T., and Lieberman, J. (2015) Visualizing Lipid-Formulated SiRNA Release from Endosomes and Target Gene Knockdown. Nat. Biotechnol. 33 (8), 870-876.

(78) Pei, D., and Buyanova, M. (2019) Overcoming Endosomal Entrapment in Drug Delivery. Bioconjugate Chem. 30 (2), 273-283.

(79) Brock, D. J., Kondow-McConaghy, H. M., Hager, E. C., and Pellois, J.-P. (2019) Endosomal Escape and Cytosolic Penetration of Macromolecules Mediated by Synthetic Delivery Agents. Bioconjugate Chem. 30 (2), 293-304.

(80) Deprey, K., Becker, L., Kritzer, J., and Plückthun, A. (2019) Trapped! A Critical Evaluation of Methods for Measuring Total Cellular Uptake versus Cytosolic Localization. Bioconjugate Chem. 30 (4), 1006-1027.

(81) Deshayes, S., Konate, K., Dussot, M., Chavey, B., Vaissière, A., Van, T. N. N., Aldrian, G., Padari, K., Pooga, M., Vivès, E., et al. (2020) Deciphering the Internalization Mechanism of WRAP:SiRNA Nanoparticles. Biochim. Biophys. Acta, Biomembr. 1862 (6), 183252. 